STEVEN A. MORRISON

Northeastern University and Brookings Institution

CLIFFORD WINSTON

Brookings Institution

\title{
Enhancing the Performance of the Deregulated Air Transportation System
}

IN A DRAMATIC BREAK with past policy, the U.S. commercial air transportation system was deregulated in 1978. Although deregulation was initially popular, primarily because it led to lower fares, public uneasiness has recently set in. ${ }^{1}$ Airport congestion and flight delays, increased concerns with safety, and rising fares in less competitive markets have all been attributed to the change in the regulatory environment. But, as illustrated in figure 1, deregulation is only one among many influences on the air transportation system. Equally influential are technological change, macroeconomic performance, and public policies besides those having to do with economic regulation. Because all these influences are interdependent, each must operate in accord with the others or the system can become disrupted.

This paper focuses on improving the air system by aligning public policy regarding mergers, airport pricing and investment, and safety with the traffic volumes and patterns that exist under deregulation. We

We are grateful to Robert Hahn, Richard Johnson, Joan Winston, and the conference participants for their comments and to Leslie Siddeley and Carol Evans for research assistance.

1. The overall decrease in fares is documented in John R. Meyer and Clinton V. Oster, Jr., eds., Airline Deregulation: The Early Experience (Boston: Auburn House, 1981); Elizabeth E. Bailey, David R. Graham, and Daniel P. Kaplan, Deregulating the Airlines (MIT Press, 1985); and Steven Morrison and Clifford Winston, The Economic Effects of Airline Deregulation (Brookings, 1986). 
Figure 1. Influences on Air System Performance

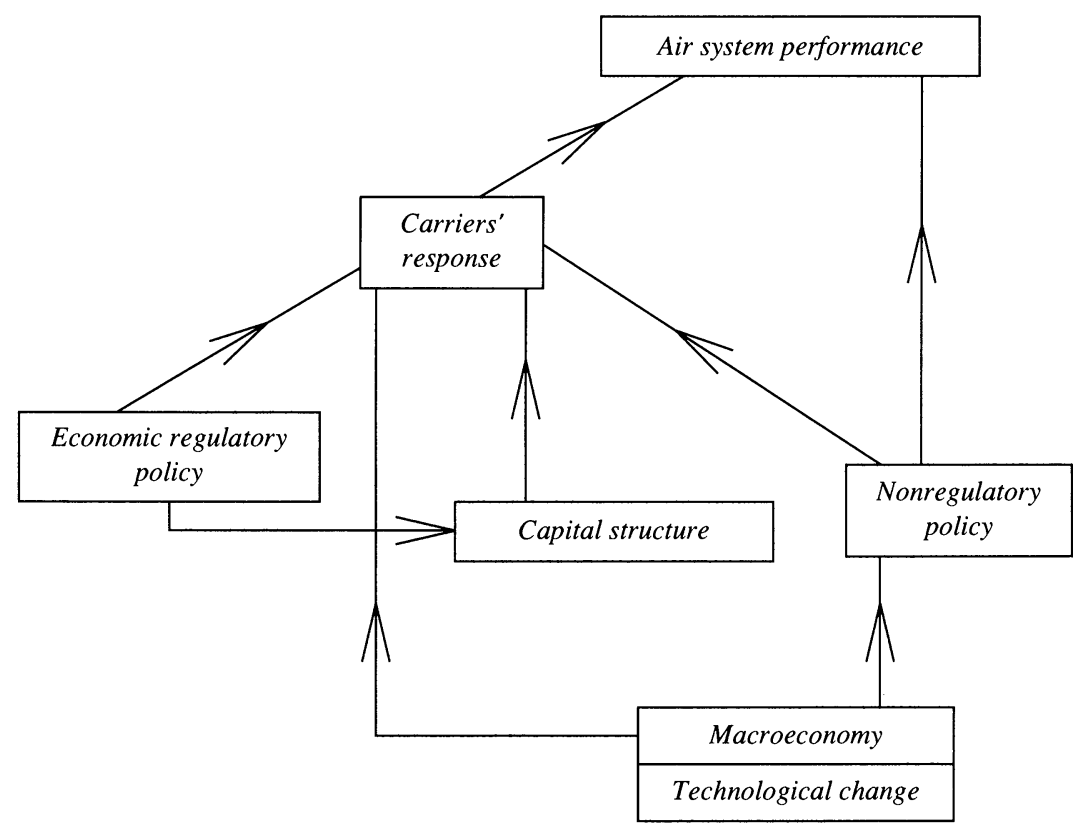

argue that the failure to bring these policies into line with the air system as it has evolved over the past ten years has generated the current dissatisfaction with the system and hampered the long-run performance of deregulation. Using an empirical model of air travelers' preferences, we analyze both the economic effects of recent airline mergers and the effects of efficient pricing and optimal runway investment at airports. We then evaluate air safety management in the deregulated environment. We conclude that the mismanagement of the regulatory transition in air transportation should motivate architects of deregulation in other industries to establish transitional advisory bodies. The cost of establishing such bodies is small; the benefits could amount to preventing the return of regulation.

\section{Air Traveler Preferences}

Traveler preferences are estimated here with a disaggregate airline carrier choice model. We constructed a random sample of air passenger 
round-trips with a single destination taken in the third quarter of 1983. We identified each traveler's choice of carrier and routing and, using the Official Airline Guide, constructed every possible carrier-routing-fare class alternative. For some markets there were hundreds of alternatives. ${ }^{2}$

The passenger is assumed to select the carrier and routing (for example, American Airlines, nonstop) that maximizes utility. The choice is influenced by the carrier's fare, service time, safety record, reputation, and promotional offerings. The traveler's fare class choice is assumed to be exogenous; that is, travelers choose a fare class based on their income, prior planning, and so on and then select a carrier and routing. ${ }^{3}$ We use the average fare for the chosen fare class and routing; high fares should decrease the likelihood of a carrier being selected. The dimensions of service time included are total travel time, transfer time, on-time performance, and schedule delay. On-time performance is defined by the Department of Transportation as the percentage of a carrier's flights arriving within fifteen minutes of the scheduled arrival time. Schedule delay is the difference between the traveler's desired departure time and the closest available departure time and is a function of the carrier's flight frequency and load factor. ${ }^{4}$ On-time performance should have a positive influence on carrier choice; the other dimensions of service time should have negative influences. The impact of carrier safety is captured

2. Air passenger round-trips are from the U.S. Civil Aeronautics Board, Ticket Dollar Value Origin and Destination Data Bank (third quarter, 1983). The final sample consisted of 3,593 round-trips covering the following five randomly selected markets: AllentownAtlanta, Burbank-San Jose, Philadelphia-Orlando, San Francisco-Portland, DaytonNew York (LaGuardia).

3. Treating fare class as endogenous would require information on traveler characteristics, such as trip planning time, income, and identity of ticket purchaser, that is unavailable. The exogeneity assumption is plausible in our context because many travelers are effectively "locked in" to a fare class by the nature of their trip. Business travelers unable to plan must take a coach fare; vacation travelers who must plan in order to get time off from work, secure hotel reservations, and so on, avail themselves of a discount fare. The implication of this assumption for the merger analysis that follows is that losses from fare increases are overstated because travelers are denied the opportunity to change their plans and secure a lower fare from a different fare class.

4. Following George W. Douglas and James C. Miller III, Economic Regulation of Domestic Air Transport: Theory and Policy (Brookings, 1974), schedule delay (SD) is calculated empirically as

$$
S D=92 F^{-0.456}+\frac{12010}{F} \cdot P^{0.5725} \cdot(S-P)^{-1.79},
$$

where $F$ is daily flight frequency, $P$ is passengers per flight, and $S$ is seats per flight. 
by a dummy variable that indicates whether the carrier was involved in a fatal accident during the preceding six months. ${ }^{5}$ Involvement in such an accident should have a negative influence on carrier choice. Promotional and reputation effects are captured by a hub dummy, a major carrier classification dummy, available frequent flier mileage and number of cities served, and passenger complaints. Airlines that are major carriers or that have a hub at a passenger's origin or destination enhance their reputations and increase the likelihood that travelers will select them. A carrier's reputation and likelihood of selection are negatively related to its volume of complaints. Finally, the extent of a carrier's network and its available frequent flier mileage are promotional advantages that have positive influences on carrier selection. ${ }^{6}$

Air traveler choices are represented by the multinomial logit model. ${ }^{7}$ Parameter estimates are presented in table 1 . The coefficients have their

5. Use of carriers' historical accident rates was less successful than the approach taken here in capturing the effect of safety on carrier choice.

6. Some carriers did not have frequent flier programs during 1983, which is why we selected this year for our sample. Specifying frequent flier mileage interactively with cities served jointly captures the convenience and promotional aspects of a carrier's network. That is, the more cities that are served, the more valuable a frequent flier mile, and the more frequent flier miles that are available, the more valuable a city served. Specification of these variables separately does not capture this interaction and leads to less statistically precise and quantitatively plausible estimates. We also attempted to identify separate effects of cities that might be particularly attractive to travelers, for example, European and California cities, but were unsuccessful. Finally, we investigated a nonlinear specification of the frequent flier mileage-cities served interaction to determine whether the marginal value of a frequent flier mile increased more than, less than, or the same as an increase in the number of cities served (and vice versa). The interaction was specified as $\beta$ (Frequent flier miles $^{\alpha}, \cdot$ cities $^{\gamma}$ ), where $\beta, \alpha$, and $\gamma$ are parameters. Estimation by a grid search procedure revealed that the (maximum) value of the log likelihood at convergence and other parameter estimates were relatively insensitive to values of $\alpha$ and $\gamma$ that clustered around 1.0. Thus these parameters were set to unity for the estimations and calculations performed here.

7. The multinomial logit choice probabilities are given by

$$
\operatorname{Prob}_{i}=\exp V_{i}\left(\beta, X_{i}\right) / \sum_{j=1}^{J} \exp V_{j}\left(\beta, X_{j}\right),
$$

where $P r o b_{i}$ is the probability of selecting carrier-routing combination $i, V_{i}$ is the mean utility of alternative $i$, which is a function of parameters denoted by $\beta$ and explanatory variables denoted by $X$. Because the traveler often had hundreds of carrier-routing alternatives to choose from, estimation was performed by using a subsample of the choice set that consisted of ten alternatives including the chosen alternative. Daniel McFadden, "Modelling the Choice of Residential Location," in Anders Karlgvist and others, eds., 
Table 1. Multinomial Logit Airline Choice Model Estimates ${ }^{a}$

\begin{tabular}{|c|c|}
\hline Explanatory variable & Coefficient $t^{\mathrm{b}}$ \\
\hline Average fare for chosen fare class (dollars) & $\begin{array}{c}-0.0291 \\
(0.0018)\end{array}$ \\
\hline Travel time (minutes) & $\begin{array}{r}-0.0165 \\
(0.0016)\end{array}$ \\
\hline Schedule delay (minutes) & $\begin{array}{r}-0.00145 \\
(0.00015)\end{array}$ \\
\hline Transfer time (minutes) & $\begin{array}{r}-0.0194 \\
(0.0029)\end{array}$ \\
\hline $\begin{array}{l}\text { Accident dummy ( } 1 \text { if carrier involved in fatal accident within past } \\
\text { six months; } 0 \text { otherwise) }\end{array}$ & $\begin{array}{r}-2.264 \\
(0.208)\end{array}$ \\
\hline Percentage of flights on time & $\begin{array}{c}0.0353 \\
(0.0067)\end{array}$ \\
\hline Complaints per 100,000 enplanements & $\begin{array}{r}-0.1309 \\
(0.0287)\end{array}$ \\
\hline $\begin{array}{l}\text { Hub dummy ( } 1 \text { if origin or destination is carrier's hub; } \\
0 \text { otherwise) }\end{array}$ & $\begin{array}{c}0.7460 \\
(0.1774)\end{array}$ \\
\hline $\begin{array}{l}\text { Frequent flier miles awarded times number of cities (domestic and } \\
\text { foreign) served by carrier (thousands) }\end{array}$ & $\begin{array}{c}0.0104 \\
(0.0018)\end{array}$ \\
\hline Major carrier dummy ( 1 if carrier is a major; 0 otherwise) & $\begin{array}{c}0.4737 \\
(0.1358)\end{array}$ \\
\hline
\end{tabular}

Sources: Fares for chosen alternatives are from U.S. Civil Aeronautics Board, Ticket Dollar Value Origin and Destination Data Bank. Fares for nonchosen alternatives, all travel times, and transfer times are from the July, August, and September 1983 Official Airline Guide. The variables needed to construct schedule delay (frequency and passengers and seats per flight) are from CAB Service Segment Data. The accident dummy is based on National Transportation Safety Board reports. Percentage of flights on time is from CAB, Schedule Arrival Performance. Data for on-time performance are from late 1981 because collection of these data ceased after the air traffic controllers strike and did not resume until 1987. Complaints are from the Department of Transportation. Because this variable is expected to have a lagged effect we used 1981 data. Use of 1983 data actually strengthened the variable's effect. Airlines provided information on their hubs and frequent flier mileage programs. Carriers' cities served and classification are from the 1983 Department of Transportation, Federal Aviation Administration and Civil Aeronautics Board, Airport Activity Statistics of Certificated Route Air Carriers, and Department of Transportation, Office of Aviation Information, "Points with Scheduled Commuter Air Service, December 1983," table 9 (computer printout).

a. Dependent variable is choice of air carrier and routing.

b. Standard errors are in parentheses. Number of observations is 3,593 ; log likelihood at zero is -8273 ; $\log$ likelihood at convergence is -1732 .

Spatial Interaction Theory and Planning Models, Studies in Regional Science and Urban Economics 3 (New York: North-Holland Press, 1978), pp. 75-96, has shown that, predicated on the assumption that the multinomial logit model is correct, this sampling procedure results in consistent estimates of multinomial logit parameters. We tested for possible violations of the independence from irrelevant alternatives property associated with the multinomial logit model applying a test suggested by Kenneth A. Small and Cheng Hsiao, "Multinomial Logit Specification Tests,' International Economic Review, vol. 26 (October 1985), pp. 619-27. We constructed choice sets composed of different random samples of ten and five alternative carrier-routing combinations. In all cases, we could not reject the null hypothesis of a multinomial logit structure. 
Table 2. Air Travelers' Values of Time

\begin{tabular}{lcc}
\hline Item & $\begin{array}{c}\text { 1983 dollars } \\
\text { per hour }\end{array}$ & $\begin{array}{c}\text { Fraction } \\
\text { of wage }\end{array}$ \\
\hline Value of travel time & 34.04 & 1.70 \\
Value of transfer time & 73.96 & 3.70 \\
Value of schedule delay & 2.98 & 0.15 \\
\hline
\end{tabular}

Source: Authors' calculations from table 1.

a. Because travel time includes transfer time, the value of transfer time is obtained as the sum of the individual travel time and transfer time marginal rates of substitution.

expected signs and are precisely estimated. The fare and service time coefficients are especially important to our analysis. A quantitative sense of their plausibility can be shown by calculating the values of time implied by the model (table 2 ). ${ }^{8}$ The value of time reflects travelers' opportunity cost and utility or disutility of travel. We find air travelers have a high value of travel time, nearly $\$ 35$ an hour, and an even higher value of transfer time. The latter value reflects the disutility to air travelers of the time spent walking through terminals and waiting at their departure gate to make a connection. ${ }^{9}$ Both estimates are broadly consistent with previous research. ${ }^{10}$ The estimated value of schedule delay may seem surprisingly low, but it is plausible because most air travelers plan ahead and can make productive use of the time spent before their actual

8. These values represent the marginal rate of substitution of money for various components of time spent in travel. They are calculated by forming the ratio of the time and fare coefficients. We attempted to estimate different time coefficients for first class and other travelers, whose value of time might be expected to differ. Our attempts proved unsuccessful largely because all passengers' service time is the same regardless of any differences in the price paid for the trip.

9. We tried to capture any additional disutility associated with the number of stops and connections by specifying routing dummies and an on-line interline dummy (the latter distinguishing between connections involving flights with the same carrier and flights with a different carrier), but these were insignificant. Transfer time itself captures the effect of extra takeoffs and landings.

10. Based on an intercity mode choice model, the value of air travel time as a fraction of the wage was found by Steven A. Morrison and Clifford Winston, "An Econometric Analysis of the Demand for Intercity Passenger Transportation," Research in Transportation Economics: A Research Annual, vol. 2 (1985), pp. 213-37, to be roughly 1.5. We are unaware of any estimates of the value of transfer time for air, but Kenneth Train, "A Structured Logit Model of Auto Ownership and Mode Choice," Review of Economic Studies, vol. 47 (January 1980), table I, estimated the value of walk access time to transit and transit transfer wait time to be 327 percent and 183 percent of the wage, respectively. The value of air transfer time reflects both walk access and wait time and should be higher than the value for transit because of the higher time cost of a missed connection. 
departure time even if it differs from their desired departure time. The delay would have a high value to those travelers who change travel plans or do not plan and simply show up at the airport to catch the earliest available flight. ${ }^{11}$ Unfortunately previous research cannot be relied upon to evaluate our finding. ${ }^{12}$ Finally, travelers place some value on carriers' on-time performance records; a 1 percentage point change is valued at $\$ 1.21$ per round-trip. Thus if the most unreliable carriers improved their on-time performance by 25 percentage points, thereby becoming the most reliable carriers, that would almost have the same value to travelers as an hour reduction in travel time.

The value placed by travelers on the remaining effects is also revealing. The disutility that travelers attach to a carrier recently involved in a fatal accident is $\$ 77.72$ per round-trip, roughly the same as an additional hour of transfer time..$^{13}$ This high value shows that the market provides strong incentives for carriers to set and maintain high safety standards. Few carriers could absorb such a disadvantage for long and remain financially solvent. Traveler complaints are less important. The average monetary loss in reputation from complaints is about $\$ 14$ per round-trip. ${ }^{14} \mathrm{Com}$ petitive advantages conferred by frequent flier programs, a hub, and a major classification are worth $\$ 32.01, \$ 25.66$, and $\$ 16.26$ per roundtrip. ${ }^{15}$ These advantages pose entry barriers that prevent airline markets

11. If disaggregation of our sample by trip purpose were possible, it could reveal that business travelers have a much higher value of schedule delay than pleasure travelers.

12. See James E. Anderson and Marvin Kraus, "Quality of Service and the Demand for Air Travel," Review of Economics and Statistics, vol. 63 (November 1981), pp. 53340; and Michael B. Abrahams, "A Simultaneous Equation Estimation of Air Travel Demand," Workshop in Transportation Economics, University of California at Berkeley, July 1980. Both incorporated schedule delay in their analyses but were unable to get a reliable estimate of its value.

13. Although it may appear that this variable captures reputation effects correlated with safety, the strength of its effect did not change when we specified a full set of individual carrier dummies. The only significant carrier dummy in all our estimations was a carrier classification dummy for major carriers.

14. We also attempted to estimate the value of traveler comfort by specifying aircraft type (for example, widebody) dummies, but these were insignificant.

15. The estimate of the value of frequent flier mileage for a round-trip is based on an average of seventy-six cities served, which yields a value of a frequent flier mile of 2.7 cents. The average round-trip distance in our sample is 1,179 miles, which gives the roundtrip value in the text. (The value of a city for the mean number of frequent flier miles is $\mathbf{4 2}$ cents.) The plausibility of the estimated value of a frequent flier mile was checked by an example. In 1983 American Airlines required participants in their frequent flier program to accumulate 60,000 miles to be eligible either for one free business class transatlantic 
from being perfectly contestable. ${ }^{16}$ A computer reservation system (CRS) is also believed to be a source of competitive advantage. We found, however, that ownership of a CRS had an insignificant effect on carrier choice. ${ }^{17}$

Our findings suggest some useful policy perspectives. Because travelers place such a high premium on service time, some passengers could benefit even if improvements necessitate higher fares. A useful approach to reduce travel time is to price the use of scarce runway capacity at airports efficiently so as to reduce congestion. Airline mergers that reduce transfer time by eliminating connections that require changing airlines (interlining) also provide traveler benefits. Merged carriers could also benefit travelers by offering a larger network and consolidated frequent flier mileage and, if they are not already, by becoming major carriers. Such benefits, however, must be weighed against fare increases due to reduced competition. The strong push of market forces for high safety standards suggests that air safety policy should be designed to reinforce rather than replace market forces.

\section{The Economic Effects of Mergers}

The success of airline deregulation can largely be attributed to the competition it unleashed. The benefits it has produced could therefore be eroded if competition is restrained. It has been widely alleged that the recent spate of airline mergers has succeeded in curbing competition

flight (Dallas-London) or for two free economy class flights. The 1983 fare for these flights ranged from $\$ 1,572$ to $\$ 1,982$, which brackets a traveler's $\$ 1,620$ (2.7 cents a mile times 60,000 miles) valuation of the frequent flier mileage. The 2.7 cents a mile estimate is probably conservative because it does not reflect other benefits from frequent flier programs such as special phone reservation numbers and preferred seat selection and boarding pass arrangements. One might argue that infrequent fliers do not place much value on the mileage, but the existence of markets where frequent flier mileage can be bought and sold suggests otherwise.

16. Steven A. Morrison and Clifford Winston, "Empirical Implications and Tests of the Contestability Hypothesis,' Journal of Law and Economics, vol. 30 (April 1987), pp. 53-66, statistically reject perfect contestability in airline markets, and Michael E. Levine, "Airline Competition in Deregulated Markets: Theory, Firm Strategy, and Public Policy," Yale Journal on Regulation, vol. 4 (Spring 1987), pp. 393-494, includes an institutional discussion of why perfect contestability is not attainable in these markets. The role of travel agents in creating entry barriers is likely to be picked up by the hub dummy.

17. The effect remained insignificant when we removed the hub dummy from the specification. 
by enabling carriers to develop "fortress" hubs where they can raise fares without fear of entry. Such fare increases are commonly blamed on the change in the regulatory environment-that is, on deregulation. Such a view of the situation, however, ignores the change in government merger policy during the $1980 \mathrm{~s}$. The change coincided with, but was not the result of, deregulation. During the regulated era, merger requests were almost always denied except when the merger was designed to keep one of the carriers from going bankrupt. During deregulation the authorities have been more lenient; just since 1986 the Department of Transportation has approved eight mergers (see table 3 ).

Judging the merits of the changed merger policy-and the mergers that have been approved under it-requires knowing its effect on airline travelers. In this section we evaluate both price and nonprice effects of six mergers approved during 1986-87 on travelers' welfare. Specifically, we analyze the mergers of American Airlines and Air California, USAir and Piedmont Airlines, USAir and Pacific Southwest Airlines, Delta Airlines and Western Airlines, Northwest Orient Airlines and Republic Airlines, and Trans World Airlines and Ozark Airlines. We do not address the carriers' various motives for merging or how their profits were affected.

The effect of the six mergers on travelers' welfare has been mixed: half the mergers have reduced it, and, assuming that frequent flier mileage continues to be provided and continues not to be subject to tax, half have improved it. If the benefits and costs of frequent flier mileage were eliminated, the mergers would reduce travelers' welfare. Furthermore, the mergers have largely foreclosed any opportunity to integrate the air transportation system more effectively, thus undermining deregulation's long-run performance.

\section{A Simple Framework for Analyzing Airline Mergers}

Our carrier choice model provides a basis for analyzing the impact of a merger on travelers' welfare because it controls for the key price and nonprice variables that are likely to be affected. Based on the model, the change in welfare, formally called the compensating variation $(C V)$, can be approximated as

$$
C V \simeq-\frac{1}{\lambda}\left(\bar{V}_{f}-\bar{V}_{\mathrm{o}}\right)
$$


Table 3. Major Airline Mergers since Deregulation

\begin{tabular}{|c|c|c|}
\hline Year & Carriers & Status ${ }^{\mathrm{a}}$ \\
\hline 1987 & $\begin{array}{l}\text { USAir-Piedmont } \\
\text { American-Air California } \\
\text { USAir-Pacific Southwest }\end{array}$ & $\begin{array}{l}\text { Approved by DOT } \\
\text { Approved by DOT } \\
\text { Approved by DOT }\end{array}$ \\
\hline 1986 & $\begin{array}{l}\text { Delta-Western } \\
\text { Texas Air-People Express } \\
\text { Texas Air-Eastern } \\
\text { Trans World Airlines-Ozark } \\
\text { Northwest-Republic }\end{array}$ & $\begin{array}{l}\text { Approved by DOT } \\
\text { Not-anticompetitive finding by DOJ } \\
\text { Approved by DOT } \\
\text { Approved by DOT after sale } \\
\text { of slots to Pan Am Shuttle } \\
\text { Opposed by DOJ } \\
\text { Approved by DOT } \\
\text { Opposed by DOJ } \\
\text { Approved by DOT }\end{array}$ \\
\hline 1985 & United-Pan American ${ }^{\mathrm{b}}$ & $\begin{array}{l}\text { Opposed by DOJ } \\
\text { Approved by DOT }\end{array}$ \\
\hline 1982 & Air Florida-Western & $\begin{array}{l}\text { Approved by CAB } \\
\text { Not consummated }\end{array}$ \\
\hline 1981 & $\begin{array}{l}\text { Continental-Western } \\
\text { Texas International-Continental }\end{array}$ & $\begin{array}{l}\text { Approved by CAB } \\
\text { Not consummated } \\
\text { Approved by CAB }\end{array}$ \\
\hline 1980 & Republic-Hughes Air West & Approved by CAB \\
\hline 1979 & $\begin{array}{l}\text { Pan American-National } \\
\text { Texas International-National } \\
\text { Eastern-National } \\
\text { Continental-Western } \\
\text { North Central-Southern }\end{array}$ & $\begin{array}{l}\text { Approved by CAB } \\
\text { Approved by CAB } \\
\text { Not consummated } \\
\text { Anticompetitive finding by CAB } \\
\text { Not consummated } \\
\text { Rejected by CAB } \\
\text { Approved by CAB }\end{array}$ \\
\hline
\end{tabular}

Sources: Jonathan D. Ogur, Curtis L. Wagner, and Michael G. Vita, "The Deregulated Airline Industry: A Review of the Evidence," Economic Issues (Federal Trade Commission, Bureau of Economics, January 1988), table II-3.

a. DOT is Department of Transportation; DOJ is Department of Justice; CAB is Civil Aeronautics Board.

b. Pan American sold its Pacific Division to United.

where $\bar{V}_{\mathrm{o}}$ is the travelers' average utility before the merger, $\bar{V}_{f}$ is the travelers' average utility following the merger, and $\lambda$ is a conversion factor to put the results in monetary units. ${ }^{18}$

Because of the linear specification of the travelers' utility function, (weighted) average utility is equal to utility evaluated at the weighted

18. The exact formula for the $C V$ is given by

$$
C V=-\frac{1}{\lambda}\left[\log \sum_{i=1}^{n} \exp \left(V_{i}\right)\right]_{V_{o}}^{V_{f}},
$$

where $V_{i}$ is the utility associated with carrier-routing $i$ and $n$ is the number of carrierrouting alternatives. This formula poses substantial computational difficulties because it 
average values for each of its components. ${ }^{19}$ This, combined with our implementation of the compensating variation formula, means that utility change, and thus welfare change, is a linear function of the changes in the weighted average values of its components. Calculating the effects of mergers is thus greatly simplified, because we need only to obtain or estimate values of those variables likely to be affected by a merger. The result is that our approximation does not take into account the substitution (that is, change in choice probabilities) that accompanies the change in the attribute of a choice alternative. In addition, we do not account for mode shifts or destination shifts in response to mergers. Not taking these effects into account means that net benefits are understated..$^{20}$

The variables in our model that contribute to utility change are average fare, transfer time, travel time, schedule delay, major carrier dummy, hub dummy, and frequent flier miles and cities served. ${ }^{21}$ As explained below, their initial 1983 (weighted average) values are used to calculate pre-merger utility, and their estimated post-merger values are used to calculate post-merger utility. ${ }^{22}$

\section{Sample}

The demand model used to evaluate the effect of mergers on air travelers is based on round-trips with the same initial and final points

requires the construction of every carrier-routing alternative (not just a subsample) for each route in each merger sample. (A given route may have hundreds of carrier-routing alternatives.) Thus pre- and post-merger values of the relevant variables would have to be calculated for thousands of carrier-routing alternatives. The approximation given in the text is obtained by taking a Taylor's expansion of the exact formula and dropping higherorder terms. The approximation's accuracy obviously depends on the degree of variation among carrier-routing utilities, which should not be too great. The value of $\lambda$ in the formula is obtained (by Roy's Identity) from the fare coefficient in the choice model.

19. The weights are equal to the fraction of passengers who selected a particular alternative.

20. To illustrate the effect of constraining substitution, suppose that travel time is valued at $\$ 30$ an hour and a merger eliminated connections that reduced travel time for one alternative by one hour. If that carrier had a pre-merger market share (that is, probability) of one-third, our approximation would evaluate this change at $\$ 10$ - the value to those one-third of travelers who previously selected that alternative. But the lower travel time for this alternative would increase its market share, thus providing benefits to more travelers. This substitution component is not captured.

21. Because of the difficulty of modeling a merger's effect on accidents, on-time performance, and complaints, we assume that these variables are unaffected by mergers.

22. Thus, variables that were initially dummy variables in the carrier choice model take on values between zero and one. 
and a single destination. Accordingly, for each of the six mergers evaluated, we selected a random sample of 115 routes on which at least one of the merger partners provided some form of service (direct, online connect, or interline connect). ${ }^{23}$ The data extracted for each of the sampled origin-destination routes included the routings (that is, carriers and connecting points) and the number of passengers who selected that routing.

\section{Fares}

Beginning with Elizabeth Bailey and John Panzar, a large literature has developed that estimates the impact of airline competition on deregulated fares. ${ }^{24} \mathrm{~A}$ basic specification that has emerged is that average fare on a route is influenced negatively by the number of actual and potential competitors on that route, and is influenced positively by route distance and the presence of a slot-controlled airport at the origin or destination..$^{25}$ Using a random sample of 112 routes, we estimate such a relationship, defining an actual competitor as one offering direct or online connecting service and a potential competitor as one serving the origin and destination airports but not the route. ${ }^{26}$ Our specification captures the notion that the fewer the actual competitors, the greater the impact of an additional one.

It has been argued that fares are higher, because of market power, when the origin or destination is a carrier's hub. We included hub dummy

23. Data from the Ticket Dollar Value Origin and Destination Data Bank (third quarter 1983). The probability of a route being included in the sample was proportional to the total number of passengers who flew on the route in the third quarter of 1983. For each sampled route we checked the Official Airline Guide for the corresponding period to see if the sampled routing represented a standard OAG routing. When it did not, that routing was eliminated. In a few cases, entire city pairs were eliminated. Thus although 115 routes for each merger were sampled, final sample sizes ranged from 111 to 115 . The sample results were inflated to estimate the effect on all trips-not just round-trips.

24. Elizabeth E. Bailey and John C. Panzar, "The Contestability of Airline Markets during the Transition to Deregulation," Law and Contemporary Problems, vol. 44 (Winter 1981), pp. 125-45.

25. A change in average fare can be interpreted as reflecting absolute changes in fare levels or a change in the percentage of discount fare seats available.

26. Routes are drawn from the Ticket Dollar Value Origin and Destination Data Bank (third quarter, 1983). Defining separate variables for carriers offering direct and connecting service did not lead to any estimation improvements. 
variables to account for this effect. An airport was considered a hub if one or more airlines serving the route hubbed at the origin or destination. ${ }^{27}$ We capture the impact of network coverage and promotional offerings on fares by including the average number of frequent flier miles awarded and cities served. As in the demand model, the effect is specified interactively; the costs and benefits of this aspect of mergers are thus evaluated in a consistent way. Finally, route density dummies were included to account for the effects of traffic density.

The results are presented in table 4 . All coefficients have the expected sign and have adequate statistical reliability. Based on this equation, if a merger were to reduce actual competitors from two to one (without changing the number of potential competitors or the hub variables), the average round-trip fare on the route would increase about 9 cents a mile, or $\$ 89$ when evaluated at the mean sample distance of 983 miles. If the number of actual competitors were reduced by one from an initial level greater than two, fares would increase less than 1 cent a mile, or about $\$ 6$ at the mean distance. If the merger affected the hub dummies, fares would go up 3-9 cents a mile (\$32-\$93) depending on the circumstances. ${ }^{28}$ Mergers that decrease by one the number of potential competitors would add an additional $\$ 3$ to fares. In percentage terms (evaluated at the average fare in the sample), the effect of losing an actual competitor ranges from 2 percent to 32 percent with no hub effects, and up to 55 percent when hub effects come into play. These predictions are reasonably similar to other models. For example, Gloria Hurdle and her associates find that if two carriers merge with no other potential or actual competition in the market, fares increase $12-33$ percent. ${ }^{29}$ If the merger reduced the number of actuals from three to two, fares would increase

27. Defining an airport as a hub if only one airline serving the route hubbed at the origin or destination did not produce any estimation improvements.

28. This would occur if the origin or destination was already a hub for one of the major carriers serving the route and the merger reduced the number of actual carriers to one (in which case this hub effect alone would cause fares to rise about $\$ 61$ ). The hub effect would also come into play if, for example, carrier A (but not carrier B) serves the route and the origin or destination is a hub for carrier $\mathrm{B}$. If the number of actual competitors serving the route remaining after merger were more than two, the hub effect alone would cause fares to increase about $\$ 32$. If the resulting carrier had a monopoly on the route, fares would increase about $\$ 93$ because of the hub effect.

29. Gloria J. Hurdle and others, "Concentration, Potential Entry, and Performance in the Airline Industry,' U.S. Department of Justice Antitrust Division Economic Analysis Group Discussion Paper, February 19, 1988, p. 24. 
Table 4. Round-Trip Fare Regression Estimates ${ }^{\mathrm{a}}$

\begin{tabular}{|c|c|}
\hline Explanatory variable & Coefficient $t^{\mathrm{b}}$ \\
\hline One-way great circle distance (miles) & $\begin{array}{c}0.4839 \\
(0.0592)\end{array}$ \\
\hline $\begin{array}{l}\text { One-way great circle distance squared (tens of thousands of miles } \\
\text { squared) }\end{array}$ & $\begin{array}{r}-0.5674 \\
(0.0896)\end{array}$ \\
\hline $\begin{array}{l}\text { Number of actual competitors on the route if actuals is } 2 \text { or less, } \\
2 \text { otherwise, interacted with distance }\end{array}$ & $\begin{array}{c}-0.0905 \\
(0.0241)\end{array}$ \\
\hline $\begin{array}{l}\text { Number of actual competitors greater than } 2 \text { on the route if } \\
\text { actuals is } 3 \text { or more, } 0 \text { otherwise, interacted with distance }\end{array}$ & $\begin{array}{c}-0.0062 \\
(0.0021)\end{array}$ \\
\hline $\begin{array}{l}\text { Dummy variable ( } 1 \text { if the number of actual competitors is } 1 \text { and } \\
\text { the origin or destination is a hub for a major carrier that serves } \\
\text { the route, } 0 \text { otherwise), interacted with distance }\end{array}$ & $\begin{array}{c}0.0946 \\
(0.0886)\end{array}$ \\
\hline $\begin{array}{l}\text { Dummy variable ( } 1 \text { if the number of actual competitors is } 2 \text { or } \\
\text { more and the origin or destination is a hub for a major carrier } \\
\text { that serves the route, } 0 \text { otherwise), interacted with distance }\end{array}$ & $\begin{array}{c}0.0327 \\
(0.0117)\end{array}$ \\
\hline $\begin{array}{l}\text { Number of potential carriers on the route (carriers serving the } \\
\text { origin and the destination but not the route), interacted with } \\
\text { distance }\end{array}$ & $\begin{array}{c}-0.0026 \\
(0.0021)\end{array}$ \\
\hline $\begin{array}{l}\text { Average number of (one-way) frequent flier miles awarded times } \\
\text { cities served }\end{array}$ & $\begin{array}{c}0.00025 \\
(0.00025)\end{array}$ \\
\hline $\begin{array}{l}\text { Slot dummy ( } 1 \text { if the origin or destination is Washington National } \\
\text { Airport [DCA], } 0 \text { otherwise) }\end{array}$ & $\begin{array}{c}9.1999 \\
(22.1071)\end{array}$ \\
\hline $\begin{array}{l}\text { Slot dummy ( } 1 \text { if the origin or destination is Kennedy } \\
\text { International Airport }[\mathrm{JFK}], 0 \text { otherwise) }\end{array}$ & $\begin{array}{l}32.2650 \\
(25.2609)\end{array}$ \\
\hline $\begin{array}{l}\text { Slot dummy ( } 1 \text { if the origin or destination is LaGuardia Airport } \\
\text { [LGA], } 0 \text { otherwise) }\end{array}$ & $\begin{array}{c}52.1567 \\
(32.9722)\end{array}$ \\
\hline $\begin{array}{l}\text { Slot dummy ( } 1 \text { if the origin or destination is Chicago O'Hare } \\
\text { Airport [ORD], } 0 \text { otherwise) }\end{array}$ & $\begin{array}{c}76.0575 \\
(21.1712)\end{array}$ \\
\hline $\begin{array}{l}\text { Nonhub-small hub dummy ( } 1 \text { if the route involves a nonhub and a } \\
\text { small hub, } 0 \text { otherwise) }\end{array}$ & $\begin{array}{c}82.0854 \\
(41.6439)\end{array}$ \\
\hline $\begin{array}{l}\text { Nonhub-medium hub dummy ( } 1 \text { if the route involves a nonhub } \\
\text { and a medium hub, } 0 \text { otherwise) }\end{array}$ & $\begin{array}{c}15.3948 \\
(56.0104)\end{array}$ \\
\hline $\begin{array}{l}\text { Nonhub-large hub dummy ( } 1 \text { if the route involves a nonhub and a } \\
\text { large hub, } 0 \text { otherwise) }\end{array}$ & $\begin{array}{c}47.0871 \\
(26.3551)\end{array}$ \\
\hline $\begin{array}{l}\text { Small hub-medium hub dummy ( } 1 \text { if the route involves a small } \\
\text { hub and a medium hub, } 0 \text { otherwise) }\end{array}$ & $\begin{array}{l}91.7666 \\
(30.1034)\end{array}$ \\
\hline $\begin{array}{l}\text { Small hub-large hub dummy ( } 1 \text { if the route involves a small hub } \\
\text { and a large hub, } 0 \text { otherwise) }\end{array}$ & $\begin{array}{l}98.6893 \\
(19.2535)\end{array}$ \\
\hline $\begin{array}{l}\text { Medium hub-medium hub dummy ( } 1 \text { if the route involves two } \\
\text { medium hubs, } 0 \text { otherwise) }\end{array}$ & $\begin{array}{l}110.2812 \\
(39.8927)\end{array}$ \\
\hline $\begin{array}{l}\text { Medium hub-large hub dummy ( } 1 \text { if the route involves a medium } \\
\text { hub and a large hub, } 0 \text { otherwise) }\end{array}$ & $\begin{array}{c}34.3480 \\
(17.0427)\end{array}$ \\
\hline $\begin{array}{l}\text { Large hub-large hub dummy ( } 1 \text { if the route involves two large } \\
\text { hubs, } 0 \text { otherwise) }\end{array}$ & $\begin{array}{c}31.7839 \\
(15.6989)\end{array}$ \\
\hline
\end{tabular}

Source: Authors' calculations.

a. Dependent variable is average round-trip fare.

b. Standard errors are in parentheses. Number of observations is $112 ; R^{2}=0.89$. 
4-12 percent. Severin Borenstein finds that a 10 percent increase in endpoint share leads to a 4.3 percent increase in fare ${ }^{30}$ So if a merger reduced actual competitors from three to two (that is, a 33 percent share goes to a 50 percent share-a 50 percent increase in share), fares would rise about 21 percent. ${ }^{31}$

The fare equation also indicates that an increase in the average number of frequent flier miles awarded and cities served increases fares. Although the magnitude is not statistically precise, it is plausible and suggests that, with competition held constant, merged carriers will recoup some but not all of the value to travelers of the network and promotional benefits of mergers in higher fares. ${ }^{32}$

In implementing the fare component of utility change, average premerger fare was calculated based on the number of actual competitors, potential competitors, and hub locations in 1983. Post-merger fares were calculated based on the changes that the merger caused in the explanatory variables. ${ }^{33}$ For example, where both merger partners served a route

30. Severin Borenstein, "Hubs and High Fares: Airport Dominance and Market Power in the U.S. Airline Industry," University of Michigan Department of Economics and Institute of Public Policy Studies Discussion Paper, March 1988.

31. A fundamental criticism of our specification is that it treats the number of competitors as exogenous. This assumption has been defended in other work by exogeneity tests that do not reject the null hypothesis of exogeneity (for example, David R. Graham, Daniel P. Kaplan, and David S. Sibley, "Efficiency and Competition in the Airline Industry," Bell Journal of Economics, vol. 14 [Spring 1983], pp. 118-38), but these tests have been criticized by Franklin M. Fisher, "Pan American to United: The Pacific Division Transfer Case,"' Rand Journal of Economics, vol. 18 (Winter 1987), pp. 492-508, as having low power. Regardless of the outcomes or merits of the exogeneity tests, we believe there are serious problems with the specification of entry. A correct specification should be based on the optimization of a complete airline network subject to fleet and manpower constraints. Current treatments simply specify market entry decisions as independent. Given our interest, we content ourselves with the similarity of our predictions to those of other (more complex) models recognizing, on the one hand, that prediction improvements could possibly be made when an appropriate specification of entry is incorporated into the analysis, but that this is unlikely to affect the fundamental welfare trade-offs and magnitudes we identify.

32. Assuming the same round-trip distance $(1,179$ miles) and number of cities (seventysix) in the demand calculation (footnote 15), a frequent flier mile raises average fare 0.9 cents (compared with the 2.7 cent valuation by travelers) and an additional city served raises average fare 14 cents (compared with the 42 cent valuation by travelers).

33. An alternative approach would be to use changes in actual fares. This was not pursued because investigations of actual pre- and post-merger fares in specific markets revealed that, even for a short time span, changes in actual fares are idiosyncratic, reflecting other effects besides mergers. 
before the merger, the merger would reduce the number of actuals by one while leaving potentials unchanged. Actuals remain unchanged when only one of the merger partners serves the route, although potentials could decrease by one or remain unchanged. If neither of the merger partners served the routes pre-merger (recall that an actual competitor provides direct or on-line connecting service) but provided interline connecting service, the merger could increase the number of actual competitors and possibly reduce potential competition. Hubs before the merger were the actual hubs of the major carriers in 1983. We assumed that post-merger hubs were the union of the hubs operated by each of the merger partners in 1983. Finally, in constructing the frequent flier-cities served effect on fares, actual cities served in 1983 were used in the pre-merger calculation. Post-merger cities served were the actual number of cities served by the merger partners after the merger.

\section{Travel Time and Transfer Time}

From the sample that we used to estimate the carrier choice model, we estimated transfer time and travel time equations. The results were (standard errors in parentheses):

$\begin{aligned} \text { Transfer time (minutes) }=\quad & 83.09 \text { (Number of interline connections) } \\ & (0.23) \\ + & 65.95 \text { (Number of on-line connections). } \\ & (0.26) \\ R^{2}= & 0.73 ; 3,593 \text { observations }\end{aligned}$

Thus if an end-to-end merger changes one interline connection to an online connection, transfer time falls by the difference between the two coefficients, about seventeen minutes.

$\begin{aligned} \text { Travel time }(\text { minutes })= & 19.23+1.204(\text { Transfer time }) \\ & (0.41)(0.004) \\ + & 0.1516(\text { Distance })+46.36(\text { Stops }) \\ & (0.0003) \quad(0.14) \\ + & 24.45(\text { Connections }) . \\ & (0.33) \\ R^{2}= & 0.96 ; 3,593 \text { observations }\end{aligned}$

Using these two equations, we calculated pre-merger transfer time and travel time based on the routings in the merger samples. Post-merger values of these variables were constructed by assuming that whenever 
the two merger partners provided interline connecting service, that same (connecting) service was now on-line, saving seventeen minutes in transfer time and twenty minutes in travel time. No other possible time effects were captured.

\section{Schedule Delay}

We estimated a frequency equation using the same sample that we used to estimate the fare equation. The dependent variable is total weekly one-way frequency on each route; the explanatory variables are distance, number of actual competitors on the route (one variable for two or fewer actual competitors, another for three or more), and a hub-actual competitor interaction term. ${ }^{34}$ The results are presented in table 5. All coefficients have the expected sign (actual competitors have a positive effect on frequency, distance has a negative effect), and exceed their standard errors. Using this equation, we calculated schedule delay assuming an average load factor (before and after merger) of 0.65 and seats per flight equal to 166 (both figures are average values for 1983). A merger that reduces actual competition on a route by one carrier will decrease flight frequency by some fifteen to twenty-three flights a week, depending on the number of actual competitors. ${ }^{35}$

\section{Major Carrier Variable}

The major carrier variable, the fraction of passenger-miles (that is, market share) on a route provided by major carriers, would not be affected by two of the mergers (Delta-Western, Northwest-Republic) because each of the partners was a major before the merger. The other four cases involved a major merging with a nonmajor-creating a larger major, and thus increasing the market share of majors on some routes.

\section{Hub Variable}

The hub variable is the fraction of passengers who fly on routes on which one of the merger partners operates a hub at the origin or

34. Including separate route density dummies did not change the other parameter estimates, but resulted in a lower $\bar{R}^{2}$.

35. Although all that we need is the change in schedule delay, because schedule delay is a nonlinear function of flight frequency, we must estimate total frequency before and after the merger, not just the change in frequency. 
Table 5. Weekly One-Way Frequency Regression Estimates ${ }^{\mathrm{a}}$

\begin{tabular}{|c|c|}
\hline Explanatory variable & Coefficient $^{\mathrm{b}}$ \\
\hline Constant & $\begin{array}{c}26.1348 \\
(19.8704)\end{array}$ \\
\hline One-way great circle distance & $\begin{array}{c}-0.0193 \\
(0.0084)\end{array}$ \\
\hline $\begin{array}{l}\text { Number of actual competitors on the route if actuals is } 1 \text { or } 2 \text {, } \\
0 \text { otherwise }\end{array}$ & $\begin{array}{l}14.8685 \\
(13.2183)\end{array}$ \\
\hline $\begin{array}{l}\text { Number of actual competitors on the route if actuals is } 3 \text { or more, } \\
0 \text { otherwise }\end{array}$ & $\begin{array}{l}22.8018 \\
(4.1064)\end{array}$ \\
\hline $\begin{array}{l}\text { Number of actual competitors on the route if the origin or } \\
\text { destination is a hub for a major carrier that serves the route, } \\
0 \text { otherwise }\end{array}$ & $\begin{array}{c}3.0909 \\
(3.0135)\end{array}$ \\
\hline
\end{tabular}

Source: Authors' calculations.

a. Dependent variable is total weekly one-way frequency on each route.

b. Standard errors are in parentheses. Number of observations is $112 ; R^{2}=0.54$.

destination. The hubs pre-merger were the actual hubs of the merger partners in 1983. Post-merger hubs were the union of the pre-merger hubs of the merger partners. A merger would increase this variable if, before the merger, one of the partners had a hub at the origin or destination of a route but did not serve the route. In all other cases this variable would be unaffected by the merger.

\section{Frequent Flier Miles and Cities Served}

Before the merger this variable is the weighted average of frequent flier miles times cities served for each of the merger partners. After the merger it is the weighted average of frequent flier miles times cities served by the new merged carrier. Cities served pre-merger is defined as actual cities served in 1983 by each of the merger partners. Postmerger cities served is the number of cities actually served by the partners post-merger. ${ }^{36}$

The effect of a merger on this variable is best illustrated by an example. Suppose carrier A (serving 75 cities) merges with carrier B (serving 85 cities), with the combined carrier serving 110 cities. Passengers who flew on airline A before the merger will now generate 47 percent $[(110 / 75)-1]$ more frequent flier miles times cities served; passengers

36. There is no evidence that the mergers affected the nature of the frequent flier programs (for example, reward levels, blackout period, and so on). 
who flew on B pre-merger will generate 29 percent more frequent flier miles times cities served.

The merger thus benefits travelers by enabling the merged carrier to offer service to more cities. The cities' value, pre- and post-merger, is enhanced by frequent flier programs, but it is assumed that the merger has not led to additional frequent flier enhancement. ${ }^{37}$ As indicated by the fare equation, there is a partially offsetting cost in higher fares due to the increase in cities. And if additional frequent flier enhancement were included as a benefit, it should be controlled for in the fare equation as a cost. We are thus consistent in neglecting both the benefits and costs of this effect, which, on net, is probably small. ${ }^{38}$

\section{Findings}

The economic effects of the mergers on travelers are presented in table 6. Half the mergers reduce welfare, and half increase it, with aggregate annual effects ranging from $-\$ 75$ million to $+\$ 71$ million. Cumulatively, the mergers have a modest impact on travelers' welfare, raising it by roughly $\$ 70$ million annually. ${ }^{39}$ The per passenger effects of each merger are also small, on average always less than $\$ 2.50$.

The effects of the mergers generally consist of a welfare loss from increased fares coupled with a welfare gain from increased frequent flier mileage and cities served. The expansion of a major carrier is a significant source of benefits in the USAir-Piedmont merger. As shown in table 7, the benefits from increased frequent flier mileage and cities served are critical. If frequent flier benefits and costs were eliminated, the mergers would lower annual welfare by approximately $\$ 335$ million in aggregate..$^{40}$

37. The benefits from frequent flier miles would actually be greater because awards offered by airlines are nonlinear and because travelers can consolidate frequent flier mileage on one carrier. It might be argued that travelers endure inefficiencies (for example, inefficient routings) to obtain frequent flier mileage. Indeed, on the basis of our carrier choice model, for a 3,000 mile cross-country trip travelers would be willing to spend an extra 2.4 hours of flight time to fly on a carrier with a frequent flier program. Mergers should reduce these inefficiencies by making frequent flier mileage easier to obtain and use.

38. We are also consistent in accounting for the benefits and higher fares from hub formation. The benefits from the formation of a major carrier are accounted for; we attempted to capture the costs in the fare equation but did not find an appreciable effect.

39. As we have indicated, net benefits are understated because we have not captured various types of substitution that would reduce fare losses.

40. This loss is also overstated because it assumes that without frequent flier enhancement, the value of the increased cities served is negligible. 


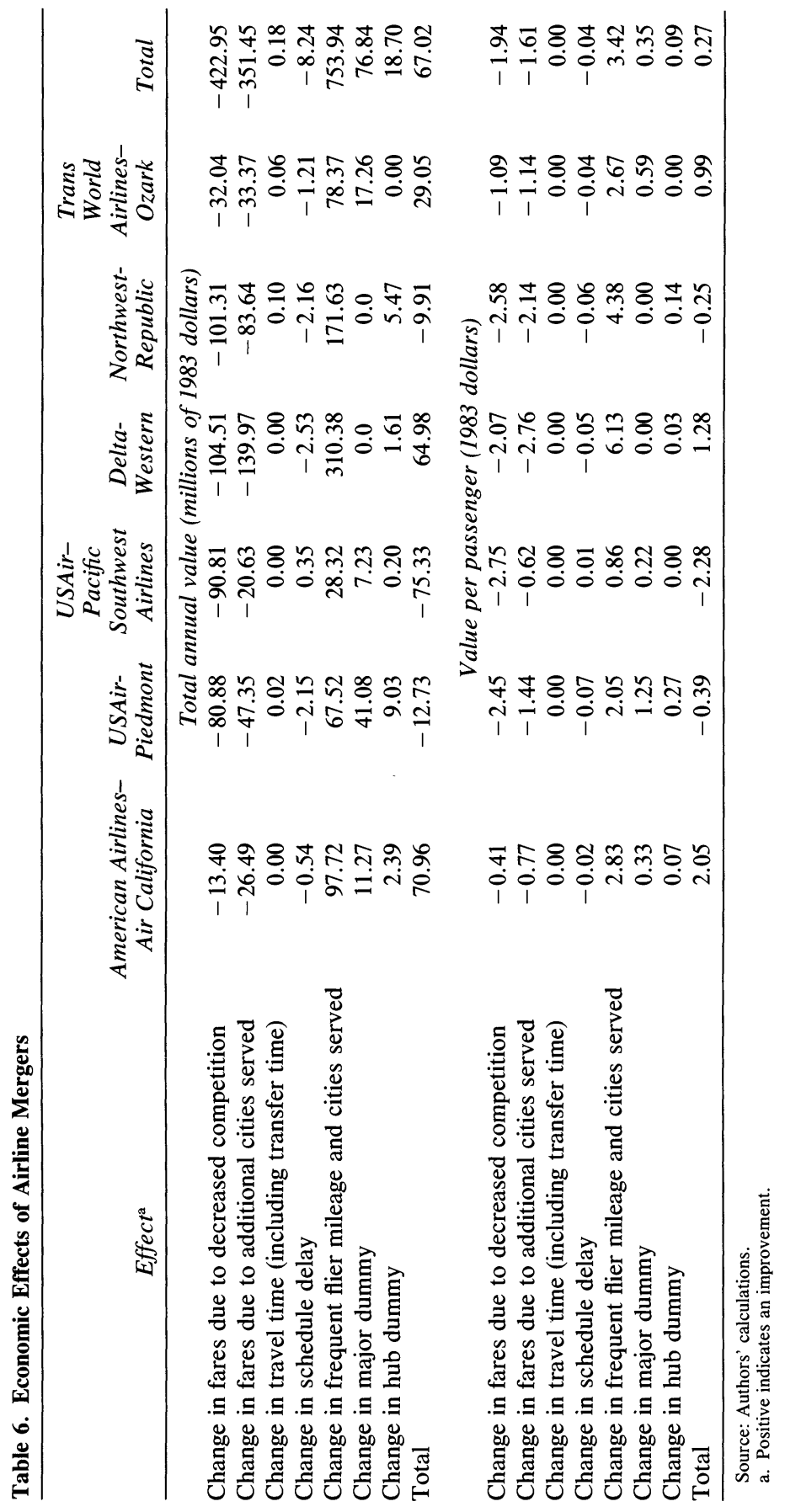


Taxing frequent flier mileage (benefits and costs are assumed to fall by one-third) would cause the aggregate effect of the mergers to become negative $\$ 67$ million.

The anticompetitive effects of each merger depend on how potential and actual competition are affected and on hub formation. As shown in table 8 , actual and potential competition are not affected in a large percentage of the routes involved in the American Airlines-Air California and USAir-Pacific Southwest Airlines mergers, so that per passenger fare losses in those cases are fairly small. A substantial number of routes in the other mergers experience a loss in potential competition, and roughly 12-25 percent of routes experience a loss in actual competition. In those cases, with the exception of TWA-Ozark, fare losses are greater.

\section{Discussion}

Most discussions of the recent airline mergers have focused on their effects on fares. We have found that when nonprice effects are included in the evaluation, three of the mergers have improved travelers' welfare. Although we have not quantified them, carriers' operating efficiencies derived from the mergers add to this positive aspect of mergers.

A major concern raised by our findings is that the mergers' offsetting positive effect on travelers is heavily dependent on airlines' continuing their promotional activities. If frequent flier programs are eliminated, the mergers' effect on travelers is negative. On the other hand, without frequent flier programs airline markets would be more contestable.

More worrisome is the impact of the mergers on deregulation. Anticompetitive effects of mergers have already eroded benefits from fare deregulation; more important, the restructuring of carriers' networks has virtually eliminated the possibility of continued progress in achieving an optimal configuration of carrier competition. ${ }^{41}$ Our earlier study found that welfare under deregulation fell short of the optimal level by $\$ 2.5$ billion (1977 dollars). ${ }^{42}$ The source of this gap was insufficient

41. It is important to bear in mind that even with the mergers, the percentage of travelers on carriers that have more than a 70 percent market share was greater in 1978 than in 1987; conversely, the percentage of travelers on carriers with less than a 30 percent market share is greater in 1987 than in 1978. See Air Transport Association, Airline Deregulation 10 Years Later: What Has It Done for the Consumer? (October 1988).

42. Morrison and Winston, Economic Effects of Airline Deregulation, pp. 58-59. This finding and the following argument should be qualified as evaluating optimal welfare independent of whether it could actually be attained. 


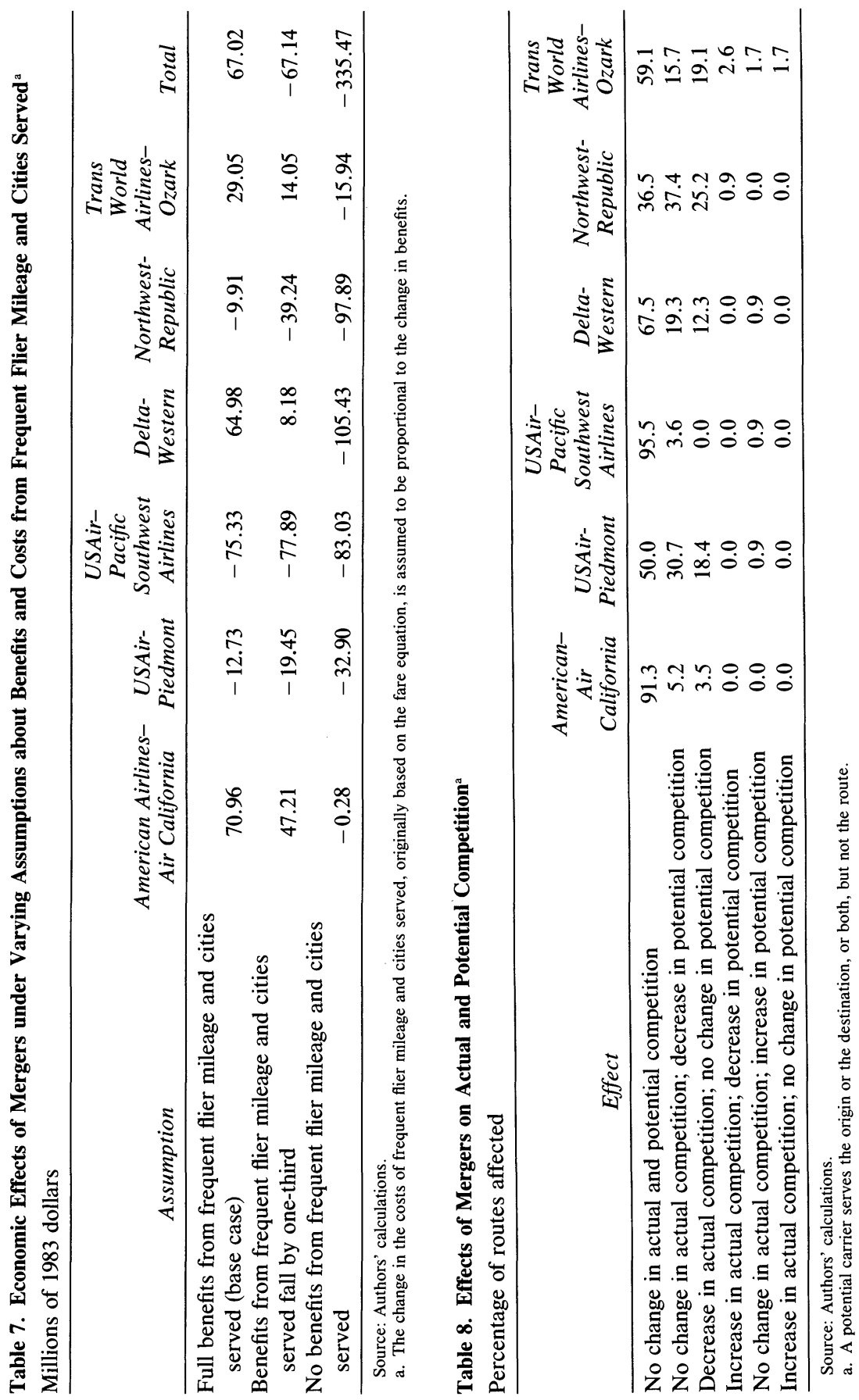


competition on medium- to low-density routes; competition on highdensity routes was adequate. Mergers have not diminished competition on high-density routes enough to threaten to erase deregulation's benefits, but by substantially foreclosing the possibility of increased competition on low- to medium-density routes, mergers have made it even less likely that deregulation will reach its full potential. ${ }^{43}$

To be sure, public policy toward mergers is not designed with this concern in mind. If the net benefits are found to be positive, as they were in half the cases analyzed here, then the affirmative decisions have arguably served the public interest. There is unfortunately no legal channel whereby the Department of Transportation could have forced TWA to acquire, for example, Eastern instead of Ozark because such a merger would generate greater social benefits.

Policy can still minimize the costs of mergers while promoting competition. Promotion of entry by foreign carriers, which would certainly require reciprocal foreign entry rights to American carriers, and prevention of airport gate and slot monopolization are two constructive steps in this direction. A third, taxation of frequent flier mileage, could actually raise travelers' welfare and provide revenues to the government by lowering entry barriers. ${ }^{44} \mathrm{~A}$ final, if controversial, step would be to broaden the concept of anticompetitive effect in any future merger evaluations to incorporate the long-run opportunity cost of network consolidation. Public policy has failed deregulation by not doing so in recent merger cases.

43. To be sure, in the absence of empirical evidence this conclusion is speculative. Unfortunately, empirical investigation of the long-run effects of the mergers on network development is very difficult. Ideally, one would like to compare the network for which the mergers are responsible with the network that would have developed in the mergers' absence. Simply using an increase (decrease) in cities served by the merged carriers as evidence that the merger has enhanced (reduced) network development is misleading because it fails to shed light on specific markets whose welfare is currently suboptimal because of insufficient competition.

44. Consider the following question: if frequent flier mileage were taxed, how much additional entry would be required for travelers to break even? The cost to travelers, assuming the benefits of 2.7 cents a mile are reduced by one-third and ignoring whatever concomitant reduction in fares may occur, is 0.9 cent a mile (1983 dollars). Morrison and Winston, "Empirical Implications and Tests of the Contestability Hypothesis," found that one additional airline entrant into a city pair market raised travelers' welfare (including fare and frequency effects) by 0.67 cent a mile ( 1983 dollars). Thus the break-even amount of additional entry required is 1.34 carriers; the break-even amount is exactly one carrier if the tax reduces benefits by one-fourth. The frequent flier awards could be taxed at the time they are spent. 


\section{Congestion and Delays}

Congestion and delays impose significant costs on passengers and carriers. According to the Federal Aviation Administration (FAA), additional time costs to passengers and additional operating costs to carriers approach $\$ 5$ billion annually. The delays are frequently attributed to deregulation and are cited as evidence that deregulation has caused service to deteriorate. Besides reregulation, proposed remedies include limiting operations at major airports and constructing new airports.

It is certainly true that deregulation and the current macroeconomic expansion have caused a tremendous surge in air travel during the past ten years. This surge and the accelerated development of hub-and-spoke operations have placed a great strain on the major airports' capacity. (The top twenty-five U.S. airports currently enplane two-thirds of the nation's passengers. $)^{45}$ But airport congestion exists largely because of a failure to price the use of, and make appropriate investments in, scarce runway capacity and air traffic control. In this section we find that replacing current landing fees, which are primarily based on aircraft weight, with marginal-cost landing fees, which account for an aircraft's contribution to congestion, would generate at least $\$ 3.8$ billion in annual net benefits largely accrued in time savings. ${ }^{46}$ Combining marginal-cost landing fees with optimal investments in runway capacity, assuming such investments are feasible, would generate at least $\$ 11.0$ billion in annual net benefits. Efficient pricing alone or in combination with efficient investment would significantly reduce the strain on airport capacity, eliminate the perceived need to limit flight operations, and postpone the expensive construction of new airports.

45. Federal Aviation Administration, FAA Aviation Forecasts Fiscal Years 19881999, FAA-APO-88-1 (U.S. Department of Transportation, February 1988), p. 112. Although some analysts have long recognized the importance of pricing runway use on the basis of congestion, no specific plan for dealing with congestion was included in the deregulation legislation. For an example of an early analysis of congestion pricing, see Michael E. Levine, "Landing Fees and the Airport Congestion Problem,"' Journal of Law and Economics, vol. 12 (April 1969), pp. 79-108.

46. Steven A. Morrison, "The Equity and Efficiency of Runway Pricing," Journal of Public Economics, vol. 34 (October 1987), pp. 45-60, discusses the history of landing fees and the increasing inefficiency of weight-based landing fees as aviation developed. 
We also find that the failure to price air congestion correctly has hurt the relative performance of deregulation. Because optimal landing fees in the regulated environment would generate $\$ 1.2$ billion in net benefits, deregulation's relative performance from inefficient allocation of capacity is lowered by $\$ 2.6$ billion. This disadvantage is overlooked by critics of deregulation.

\section{Optimal Runway Pricing and Investment}

This analysis is based on an equilibrium model of optimal pricing and investment. The economic theory that underlies the model and the equations that guide its implementation are presented in the appendix. A nontechnical summary is provided here. Basically, each takeoff and landing imposes costs on other users in the form of delay. For runway use to be optimal, users must be charged fees that reflect the (external) costs that they impose on other users and on the airport authority. These are called marginal-cost fees. In the long run, capacity should be added until the extra cost of the added capacity equals the attendant reduction in delay costs. This is the basis for optimal runway investment.

To calculate marginal-cost fees and optimal capacity and to evaluate their effects, we need an airport cost function including both capital costs and operating costs, a delay function expressing the relationship between runway use and delay, and a set of airport user demand functions.

\section{Airport Maintenance, Operation, and Administrative Costs}

Morrison has elsewhere estimated the marginal maintenance, operations, and administrative costs of airports to be $\$ 12.34$ (1976 dollars) per air carrier operation with a statistically insignificant effect of general aviation operations on costs. ${ }^{47}$ This figure was inflated to 1988 dollars using an index (provided by the Air Transport Association) of 1988 landing fees relative to 1976 landing fees (1.79). The resulting marginal maintenance, operation, and administrative expense is $\$ 22.09$ per air carrier operation and zero per general aviation operation.

47. Steven A. Morrison, "Estimation of Long-Run Prices and Investment Levels for Airport Runways," Research in Transportation Economics: A Research Annual, vol. 1 (1983), p. 117. 


\section{Runway Construction Costs}

The marginal construction cost in 1976 of a square foot of runway was estimated to be $\$ 14.99 .^{48}$ Inflating this figure to 1987 dollars using the Federal Highway Administration's highway construction cost index (1.84) gives $\$ 41.4$ million as the marginal construction cost of a 10,000 feet by 150 feet runway. To convert this lump-sum cost into a (daily) flow, we assumed a base-case real interest rate of 6 percent. ${ }^{49}$

\section{Land Requirements}

We assumed that no additional land is required for airport expansion; that is, those airports that can expand can do so on land they already own, which has no alternative uses. ${ }^{50}$ However, this assumption makes investment look feasible in cases where it is not, or at least may make capacity appear (to the model) less expensive than it actually is. Although runway expansion may not be feasible at some airports, other capacityenhancing mechanisms are and will be available. ${ }^{51}$ For this reason, in addition to presenting figures for the optimal number of runways assuming that that method of capacity expansion is feasible, we also present figures that show the gross value of additional (runway or non-runway) capacity.

\section{Delay}

The principal data source for estimating the relationship between airport activity and arrival and departure delay $\left(T_{A}\right.$ and $T_{D}$ in the appendix $)$ was the Department of Transportation's Airline Service Quality Performance data set for May $1988 .{ }^{52}$ Among other variables, this data set

48. Ibid., p. 110.

49. To test the sensitivity of our results to this assumption, we also used 3 percent and 9 percent.

50. We also assume the absence of environmental (noise) effects.

51. For an extensive discussion of capacity-enhancement mechanisms, see Air Transport Association of America, "Airport Capacity Assessment at the 22 Pacing Airports," March 14, 1985, and "Airport Capacity Assessment at the Next 17 Pacing Airports," November 13, 1986.

52. By this time the air traffic control work force was sufficiently rebuilt so as not to influence our findings. Our results were consistent with results we obtained based on a smaller sample of airports for October 1987. 
contains the actual departure and arrival times for flights by airlines with 1 percent or more of industry-scheduled passenger revenue to or from airports with 1 percent or more of total domestic enplanements. Delay per flight on Tuesday, May 17, 1988, was calculated by subtracting undelayed flight time from actual flight time for all flights in the data set between thirty-one airports of interest. ${ }^{53}$ We then used regression analysis to apportion this total flight delay into its arrival and departure delay components, with a series of dummy variables for independent variables. Each dummy variable corresponded to a particular hour of the day at a particular airport for actual arrivals and departures. An arrival (departure) dummy variable was set to one if the flight in question arrived (departed) from the airport represented by the dummy variable during the hour represented by that dummy variable. The dummy variable was set to zero otherwise. For example, if a flight left San Francisco at 7:30 A.M. and landed at Los Angeles at 8:30 A.M., the dummy variable representing departures from San Francisco between 7:00 A.M. and 7:59 A.M. would be set to one as would the dummy variable representing arrivals at Los Angeles between 8:00 A.M. and 8:59 A.M. All other dummy variables would be set to zero. However, in this form the equation cannot be estimated because it suffers from perfect multicollinearity. ${ }^{54}$ To overcome this problem, twenty-five coefficients were set to zero-those representing arrival and departures that occurred at airports when the weather was above Visual Flight Rules minimums (ceiling greater than 1,000 feet and visibility greater than three miles) and when fewer than three operations an hour per runway were taking place. The resulting regression had 4,436 observations (flights) on 1,077 (dummy) variables, with an $R^{2}$ of 0.833 . The coefficients of the dummy variables-representing arrival and departure delay by hour for thirtyone airports-were then used as dependent variables in estimating the relationship between airport activity and arrival and departure delay.

After eliminating negative coefficients and those for which corresponding values for the independent variables were not available, we

53. Because scheduled flight time includes some delay, we assumed undelayed flight time for a route to be the minimum flight time achieved by any flight in the data set on that route during May 1988. An alternative approach is to fit a statistical model that predicts (undelayed) technologically feasible flight times. This approach was attempted here but led to unsatisfactory flight time predictions for many routes.

54. Because each flight involves one departure and one arrival, the sum of all the arrival-related dummy variables equals the sum of all departure-related dummy variablesboth sums resulting in a vector of ones. 
Table 9. Arrival Delay Regression Estimates ${ }^{\mathrm{a}}$

\begin{tabular}{cc}
\hline \multicolumn{1}{c}{ Explanatory variable } & Coefficient $^{\mathrm{b}}$ \\
\hline General aviation arrivals per runway $^{\mathrm{c}}$ & 0.0087 \\
& $(0.0494)$ \\
General aviation departures per runway $^{\mathrm{c}}$ & 0.0829 \\
& $(0.0518)$ \\
Air carrier arrivals per runway & 0.1681 \\
& $(0.0441)$ \\
Air carrier departures per runway & \\
& 0.0812 \\
\end{tabular}

Source: Authors' calculations.

a. The dependent variable is the log of arrival delay.

b. Standard errors are in parentheses. Number of observations is $229 ; R^{2}=0.61$.

c. Including commuter aviation.

d. Including military aviation.

had 229 observations of arrival delay and 265 observations of departure delay. The functional form chosen for estimation was the semilog form in which the log of delay was regressed on general aviation arrivals per runway, general aviation departures per runway, air carrier arrivals per runway, and air carrier departures per runway. ${ }^{55}$ This functional form has the advantage of being homogeneous of degree zero in the activity variables and runways (that is, delay is a function of the volume-capacity ratio). In addition, marginal delay is an increasing function of the activity variables and a decreasing function of runway capacity. No constant term was used in the specification because delay should be small (zero) when airport activity is zero. Finally, although data were collected, weather is not held constant because it would be inappropriate to set fees based on actual as opposed to average weather patterns.

The results of the regressions are shown in tables 9 and 10. All coefficients have the expected positive sign, with most exhibiting a high degree of statistical reliability. The coefficients are interpreted as the percentage increase in average delay caused by a one unit change in the independent variable. Thus if general aviation departures per runway increased by one, average arrival delay would increase 8.29 percent. Also, a coefficient times its independent variable equals the elasticity of average delay with respect to the independent variable of interest. Thus

55. Commuter airlines were included in the general aviation variable, and military flights were included in the air carrier variable. Hourly arrival and departure data were obtained from FAA Tower Logs for each of our airports. The number of runways was obtained from AOPA's Airports USA (Frederick, Md.: Aircraft Owners and Pilots Association, 1988). 
Table 10. Departure Delay Regression Estimates ${ }^{a}$

\begin{tabular}{cc}
\hline Explanatory variable & Coefficient $^{\mathrm{b}}$ \\
\hline General aviation arrivals per runway $^{\mathrm{c}}$ & 0.0820 \\
& $(0.0423)$ \\
General aviation departures per runway $^{\mathrm{c}}$ & 0.1257 \\
& $(0.0421)$ \\
Air carrier arrivals per runway & 0.0790 \\
& $(0.0366)$ \\
Air carrier departures per runway & \\
& 0.1457 \\
\end{tabular}

Source: Authors' calculations.

a. The dependent variable is the log of departure delay.

b. Standard errors are in parentheses. Number of observations is $265 ; R^{2}=0.73$.

c. Including commuter aviation.

d. Including military aviation.

if there were twenty air carrier departures per runway, a 1 percent increase in air carrier departures would cause a 2.9 percent increase in average departure delay.

With the exception of general aviation arrivals in the arrival delay regression, the pattern of results is that general aviation and air carriers have approximately the same effect on delay, and thus under optimal pricing would pay similar fees. ${ }^{56}$ Also, as expected, arrival operations have the greatest impact on arrival delay while departure operations have the greatest effect on departure delay.

\section{Demand Specification}

The set of airport user demand functions are simple constant-elasticity demand functions of the form

$$
Q_{A t}^{i}=A_{A t}^{i} \cdot\left(P_{A t}^{i}\right)^{-\eta}
$$

for arrivals and

$$
Q_{D t}^{i}=A_{D t}^{i} \cdot\left(P_{D t}^{i}\right)^{-\eta}
$$

for departures,

56. The small effect of general aviation arrivals on arrival delay could be explained by air traffic control procedures. Although the system supposedly operates on a "first-come first-served" basis, air traffic controllers may give landing preference to larger aircraft. 
where $Q_{A t}^{i}$ is the quantity of arrivals $(A)$ by a user in class $i$ during period $t, A_{A t}^{i}$ is a constant (a scaling parameter), $P_{A t}^{i}$ is the "gross price" of an arrival discussed below, and $\eta$ is an elasticity parameter. The departure (D) variables are similarly defined. The gross price of an arrival or departure includes all those costs borne by the airlines and the passengers, specifically (undelayed) aircraft operating cost and passenger time costs, delay costs to both the airline and the passengers, and landing fees.

To implement this model we divided the aircraft operating at each of the sample airports into six mutually exclusive categories: international, cargo, majors and nationals, commuter, other commercial (primarily regionals), and general aviation. The time periods indexed by $t$ were defined to be one hour beginning on the hour for May 17, 1988. We assumed that during each hour of the day each user class and operation type (that is, arrival or departure) operated a single aircraft type over a single flight distance. In particular, we assumed that for each hour of the day the aircraft type operated by a given user class and operation type was the median-sized aircraft actually operated by that class at each of the sample airports. Similarly we assumed that the distance flown by that user class and operation type for a given hour of the day was the median distance actually flown by all members of that class during the same period. Hourly aircraft operating cost data were obtained from the FAA, specifying both the marginal cost of air and ground operations. ${ }^{57}$ To construct passenger time costs we assumed a 65 percent load factor for each of the aircraft types involved, and, as our base case, we valued passenger time at $\$ 42.55$ an hour. ${ }^{58}$ Total aircraft operating cost and passenger time costs were obtained by multiplying the hourly values

57. In particular, the FAA provided us with such data for United Airlines for eleven aircraft types during 1986. To use these data for the many aircraft types operating at the airports in our sample, we regressed each of the operating cost variables on seats, for example, Cost $=A(\text { Seats })^{\alpha}$. The results were Air cost $=18.99(\text { Seats })^{0.86}\left(R^{2}=0.85\right)$ and Ground cost $=19.89$ (Seats $)^{0.80}\left(R^{2}=0.78\right)$. These predicted costs were then inflated to 1988 dollars based on an index of the relative aircraft operating cost for 1988 and 1986 (1.18).

58. This value of passenger time was based on the value of time from our carrier choice model. That value, from table 2 , is $\$ 34.04$ expressed in 1983 dollars. This was inflated to 1988 dollars by using an index of the income of air travelers in 1988 relative to 1983 (1.25). We also used a value of time of one-half of the above figure to evaluate the sensitivity of our results to the assumed value of time. Time for general aviation pilots and passengers was valued at 1.5 times the base amounts because of their higher incomes. 
times trip time for the assumed flight distance. Delay cost was obtained similarly by multiplying the value of a minute's air or ground time by the minutes of air or ground delay predicted by our delay model for that airport and time of day.

We assumed as our base case a value of the gross price elasticity of demand of 1.5. ${ }^{59}$ Finally, the values of the constant $A$ for each user class, time period, and operation type were calculated so that given the assumed values of the other variables, the values of the quantities for each user class, operation type, and time period were each equal to their actual values at each of the airports involved. ${ }^{60}$

Using the theoretical model described in the appendix, we calculated the net benefit-maximizing quantity of use in both the short run and the long run for each of the sample airports. The output includes the effect of such optimization on users from each user class who, despite the (usually higher) fees, continue to use the facility, as well as the effect on those users who are "tolled off" the facility. Changes in net airport revenue are also produced. From the results for the thirty-one airports in our sample, we produce aggregate estimates for the United States by inflating our numbers by the ratio of total enplanements in the United States (in 1986, the latest available data) to total enplanements at our sample airports in the same year. ${ }^{61}$

Because of the properties of the demand functions used, the model does not capture various types of feasible "substitutions." The results presented should thus be viewed as conservative. For example, the model assumes zero intertemporal cross elasticity of demand; that is, the demand for use of the airport in a given hour is a function only of the price for that hour. Thus the model does not capture "peak spreading." Other variables assumed constant in the model that would no doubt

59. This figure is consistent with the aggregate elasticity measure in Arthur De Vany, "The Revealed Value of Time in Air Travel," Review of Economics and Statistics, vol. 56 (February 1974), pp. 77-82. Besides the base case we also use values of 1.25 and 1.75 to test the sensitivity of our results to this assumption. It is possible that, because of contractual relationships between commuters and jet carriers, commuters' elasticities are smaller than our lower bound. This consideration, if relevant, would reduce the benefits from congestion pricing.

60. Values for $Q_{A}$ and $Q_{D}$ were obtained from the Official Airline Guide (Airport Chronological Listing for each of the airports). Values of the $Q$ 's for general aviation were obtained from the air traffic control towers.

61. The sample airports enplane more than 50 percent of total U.S. air travelers. 
change if optimal fees were introduced are load factors (which would increase) and aircraft types (increase in size), as well as routing (which would involve less hub-and-spoke). By limiting the responses of users to new fees, the model understates welfare gains and overstates welfare losses. ${ }^{62}$

\section{Findings}

The economic effects of setting marginal-cost landing fees under current and optimal investment are presented in table 11. Marginal-cost pricing under current investment leads to significant gains in net welfare, totaling $\$ 3.8$ billion a year (in 1988 dollars) using our base-case assumptions. ${ }^{63}$ Landing fees increase substantially, and there is some loss from travelers forced from the air market, but these losses are more than offset by the improvement in airport finances. (Because we do not account for intertemporal substitution by aviation activity or for changes in carriers' networks, the amount of redistribution is overstated.) Thus reduced carrier operating costs and, to a greater extent, lower passenger delay costs are the net effects of this policy.

The second column of the table shows that optimal pricing would generate considerably fewer benefits in a regulated environment. We assume that if regulation were still in effect, traffic volume would be 20 percent less than under deregulation. ${ }^{64}$ Under this assumption, the annual benefits from optimal pricing total $\$ 1.2$ billion. Because of the exponential form of the delay function, an expansion in traffic causes a much greater rise in delay, thus dramatically increasing the need for congestion pricing. Failure to allocate air capacity efficiently in response to the traffic

62. Welfare gains will also be understated because of the method we used to "estimate" the demand curve for airport use. At slot-controlled airports our approach will underestimate demand and thus underestimate the benefit of congestion pricing.

63. Under alternative assumptions regarding travelers' value of time and airport users' demand elasticity (initially set at $\$ 42.55$ an hour and 1.50 , respectively), the welfare gain ranges from $\$ 2.2$ billion (elasticity $=1.25$, value of time $=\$ 21.27$ ) to $\$ 4.0$ billion (elasticity $=1.75$, value of time $=\$ 42.55$ ).

64. Morrison and Winston, Economic Effects of Airline Deregulation, found that deregulation led to fares that are 25 percent lower than they would have been under regulation. Assuming a trip generation price elasticity of 1.0 implies that deregulation is responsible for a 25 percent increase in traffic volume. Of course, even if there were no increase in traffic, the accelerated development of hub-and-spoke networks under deregulation has placed greater strain on major airports' capacity. 
Table 11. Annual Economic Effects of Optimal Pricing and Optimal Pricing and Investment

Billions of 1988 dollars

\begin{tabular}{|c|c|c|c|}
\hline \multirow[b]{2}{*}{ Effect } & \multicolumn{3}{|c|}{$\begin{array}{c}\text { Change relative to current pricing } \\
\text { and investment practice }{ }^{\mathrm{a}}\end{array}$} \\
\hline & $\begin{array}{l}\text { Optimal } \\
\text { pricing }\end{array}$ & $\begin{array}{l}\text { Optimal } \\
\text { pricing under } \\
\text { "regulation" }\end{array}$ & $\begin{array}{l}\text { Optimal } \\
\text { pricing } \\
\text { and } \\
\text { investment }\end{array}$ \\
\hline \multicolumn{4}{|l|}{ Continuing passengers } \\
\hline Carriers' operating costs & 1.23 & 0.41 & 2.77 \\
\hline Delay savings & 3.62 & 1.20 & 7.91 \\
\hline Landing fees & -11.58 & -5.41 & -0.14 \\
\hline Total & -6.73 & -3.80 & 10.54 \\
\hline Surplus of tolled-off passengers & -0.95 & -0.41 & -1.24 \\
\hline \multicolumn{4}{|l|}{ Total continuing and tolled-off } \\
\hline passengers & -7.68 & -4.21 & 11.78 \\
\hline Airport revenues and costs & 11.50 & 5.36 & -0.77 \\
\hline Total welfare & 3.82 & 1.15 & 11.01 \\
\hline
\end{tabular}

Source: Authors' calculations.

a. Positive indicates an improvement.

induced by deregulation has put deregulation at a $\$ 2.6$ billion disadvantage in comparisons of the regulatory environments.

Optimal pricing combined with optimal investment leads to even greater gains, totaling $\$ 11.0$ billion a year. ${ }^{65}$ In addition, the transfer of resources is much smaller. Landing fees increase only $\$ 0.1$ billion in aggregate, and even with the increase in fees, airport finances decline slightly because of additional capacity expenses. ${ }^{66}$ The bulk of the effects are large savings in carriers' operating costs and in passenger delay costs.

The subsequent tables present more detailed explanations of our findings. Table 12 shows the effects of the policies on fees, delay, and runway capacity. Under optimal pricing at current investment, landing fees rise more than tenfold at major congested airports, but rise much less at the less congested airports. When optimal pricing is combined

65. This estimate ranges under alternative values of key parameters from $\$ 6.1$ billion (elasticity $=1.25$, value of time $=\$ 21.27$, interest rate $=9$ percent) to $\$ 12.0$ billion (elasticity $=1.75$, value of time $=\$ 42.55$, interest rate $=3$ percent).

66. The decline in airport finances may appear to contradict the constant returns to scale in airport capacity implicit in our model. Our finding simply indicates that current aggregate annual landing fee revenue exceeds (annualized) runway construction costs. 
Table 12. Landing Fees, Delay, and Runways under Optimal Pricing and Optimal Pricing and Investment, Selected Airports

\begin{tabular}{|c|c|c|c|c|c|}
\hline Item & $\begin{array}{l}\text { Washington } \\
\text { (National) }\end{array}$ & $\begin{array}{c}\text { Denver } \\
\text { (Stapleton) }\end{array}$ & $\begin{array}{c}\text { New York } \\
\text { (LaGuardia) }\end{array}$ & $\begin{array}{l}\text { Chicago } \\
\text { (O'Hare) }\end{array}$ & $\begin{array}{l}\text { San Antonio } \\
\text { (International) }\end{array}$ \\
\hline \multicolumn{6}{|l|}{$\begin{array}{l}\text { Landing fees per } \\
\quad \text { passenger (dollars) }\end{array}$} \\
\hline Initial & 0.75 & 0.92 & 3.22 & 1.20 & 0.50 \\
\hline Optimal pricing & 9.81 & 9.26 & 32.05 & 10.89 & 2.52 \\
\hline $\begin{array}{l}\text { Optimal pricing and } \\
\text { investment }\end{array}$ & 1.32 & 1.29 & 1.15 & 1.12 & 1.52 \\
\hline \multicolumn{6}{|c|}{ Average delay (minutes) } \\
\hline Initial & 9.3 & 7.3 & 27.9 & 8.4 & 3.0 \\
\hline Optimal pricing & 5.5 & 5.4 & 12.8 & 6.0 & 2.5 \\
\hline $\begin{array}{l}\text { Optimal pricing and } \\
\text { investment }\end{array}$ & 1.8 & 1.8 & 1.8 & 1.7 & 2.0 \\
\hline \multicolumn{6}{|l|}{ Runways } \\
\hline Initial & 3.0 & 5.0 & 2.0 & 7.0 & 3.0 \\
\hline $\begin{array}{l}\text { Optimal pricing and } \\
\text { investment }\end{array}$ & 11.7 & 16.9 & 17.7 & 29.2 & 4.4 \\
\hline
\end{tabular}

Source: Authors' calculations.

with optimal investment, fees increase only slightly and actually fall in two instances. Delays at major congested airports are reduced as much as 50 percent under optimal pricing, and as much as 90 percent when optimal investment is also introduced. Finally, significant increases in runway capacity are called for, indicating that congestion has been exacerbated by an underinvestment in capacity. ${ }^{67}$

The distributional effects of the policies among aviation activity, presented in table 13, reveal that under optimal pricing the greatest per passenger losses are experienced by general aviation followed by commuters. The implication is that both are substantially undercharged under current pricing policy. Under optimal pricing and optimal investment, commercial carriers and commuters experience a net gain, but general aviation's increased landing fees still offset reductions in their operating costs and delay. Consequently, general aviation and commuter operations are significantly curtailed under optimal pricing (table 14); commercial carriers' operations are less affected. Commercial carrier and commuter operations expand under optimal pricing and investment, but general aviation activity is still reduced.

67. This obviously has also increased the strain on air traffic controllers. 


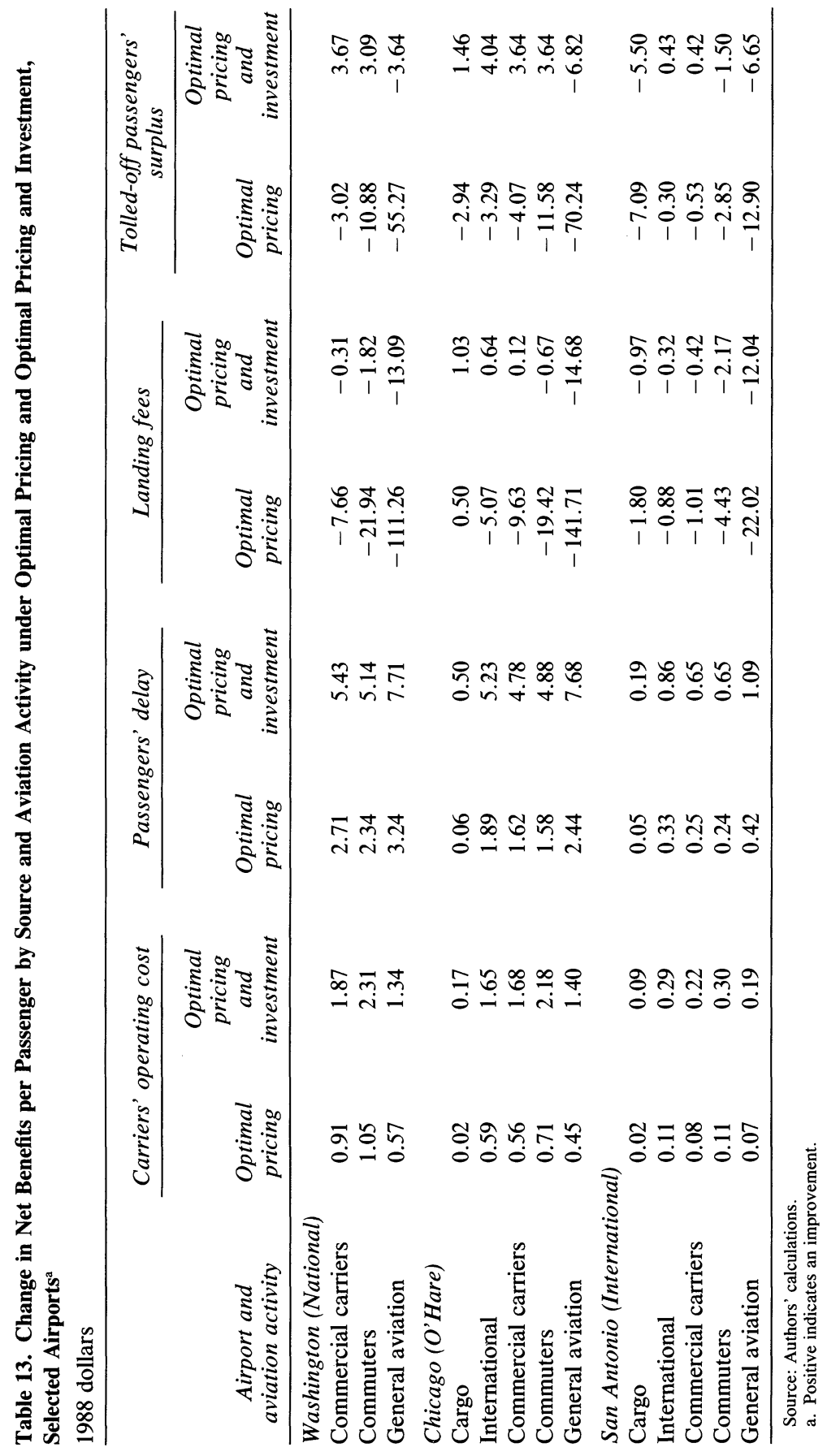


Table 14. Daily Aviation Operations under Optimal Pricing and Optimal Pricing and Investment, Selected Airports

\begin{tabular}{lrcr}
\hline & \multicolumn{3}{c}{ Total operations } \\
\cline { 2 - 4 } \multicolumn{1}{c}{$\begin{array}{c}\text { Airport and } \\
\text { aviation } \text { activity }\end{array}$} & & & $\begin{array}{c}\text { Optimal } \\
\text { pricing } \\
\text { and } \\
\text { investment }\end{array}$ \\
\hline Washington (National) & Initial & $\begin{array}{c}\text { Optimal } \\
\text { pricing }\end{array}$ & 717 \\
Commercial carriers & & & 140 \\
Commuters & 635 & 583 & 278 \\
General aviation & 122 & 82 & \\
Chicago (O'Hare) & 288 & 138 & 28 \\
Cargo & & & 39 \\
International & 27 & 26 & 1,821 \\
Commercial carriers & 38 & 37 & 427 \\
Commuters & 1,671 & 1,523 & 74 \\
General aviation & 365 & 250 & 26 \\
San Antonio (International) & 78 & 31 & 4 \\
Cargo & & & 209 \\
International & 28 & 24 & 19 \\
Commercial carriers & 4 & 4 & 280 \\
Commuters & 208 & 206 & \\
General aviation & 20 & 18 & \\
\hline
\end{tabular}

Source: Authors' calculations.

\section{Practical Considerations and Policy}

Our findings suggest that either optimal pricing or optimal pricing and investment would generate substantial benefits, but that these gains are achieved with minimal redistribution only if optimal investment is combined with optimal pricing. Unfortunately, the obstacles to building additional runways are formidable. Airports that own enough land to accommodate expansion face strong opposition from nearby residents and from environmental groups when they propose runway expansion. Airports that must acquire land not only face this opposition, but require billions of dollars to finance acquisition and development costs. ${ }^{68}$ Politically difficult as the policy of building additional runways is, its benefits, as shown in table 15, could be huge. For that reason, and because additional capacity is so important in softening the distributional effects

68. For example, site preparation and land acquisition costs for an expansion at the Seattle airport were estimated by FAA officials to be $\$ 2.75$ billion. 
Table 15. Gross Annual Value of an Additional Runway's Capacity

Millions of 1988 dollars

\begin{tabular}{lcc}
\hline \multicolumn{1}{c}{ Airport } & $\begin{array}{c}\text { Current } \\
\text { pricing }\end{array}$ & $\begin{array}{c}\text { Optimal } \\
\text { pricing }\end{array}$ \\
\hline Washington (National) & 91.7 & 40.9 \\
Denver (Stapleton) & 75.6 & 44.9 \\
New York (LaGuardia) & 583.3 & 192.3 \\
Chicago (O'Hare) & 138.1 & 77.5 \\
San Antonio (International) & 5.5 & 4.6 \\
\hline
\end{tabular}

Source: Authors' calculations.

of optimal pricing, capacity expansion should receive serious consideration. ${ }^{69}$

Optimal pricing can be easily implemented,${ }^{70}$ but several distributional issues arise because optimal pricing results in higher landing fees and a net loss to those passengers whose valuation of delay savings does not offset the higher fares they will have to pay. ${ }^{71} \mathrm{We}$ argue that some compensation can be made and that remaining political opposition can be overcome, but the latter will require the federal government to take a strong leadership role.

Currently, federal law limits the revenue airports can raise from pricing their services. And airports receive federal support for traffic control and grants for "airside" improvements. ${ }^{72}$ Most of the federal support is from the aviation trust fund, which is primarily composed of revenues from the 8 percent tax on each ticket. In the interest of promoting efficient expenditure of federal funds in a deficit-conscious era, the Department of Transportation should require that airports can

69. Kenneth A. Small, Clifford Winston, and Carol A. Evans, Road Work: A New Highway Pricing and Investment Policy (Brookings, 1989), found that optimal investment in road durability was critical in softening the distributional effects of optimal road wear pricing.

70. FAA airport towers currently record all takeoff and landing activity. Thus little additional bookkeeping would be required to implement congestion pricing. Distribution of hourly takeoff and landing fee schedules would also be easy.

71. Given the structure of the airline industry, increased landing fees to carriers would likely be passed on to their passengers in higher fares. However, because we have held the network and schedules fixed, we do not allow carriers to adjust their routings and flight times to minimize the burden of the congestion fees.

72. According to Congressional Budget Office, Policies for the Deregulated Airline Industry (July 1988), table 6, federal grants support 20-25 percent of large- and mediumhub airport investment costs. Bond proceeds support the rest of these costs. 
receive federal funds only if they show that their facilities are being efficiently used. DOT should then recommend congestion pricing as a way to meet this criterion for funding. In addition, legislation must relax airport revenue constraints. ${ }^{73}$

Because congestion pricing allocates airport runway capacity and airspace efficiently and substantially increases airport revenues, DOT should argue for a reduction in the ticket tax to provide some compensation for commercial carrier and commuter passengers. ${ }^{74}$ The government should also restrict airport use of the increased revenue to efficient investments that help reduce congestion. General aviation will still suffer losses and will most likely use their national organization and influence with local airport authorities to block implementation of congestion pricing, but they are unlikely to succeed if DOT strongly supports congestion pricing.

\section{Alternative Policies}

Alternative policies include slot controls, construction of more airports, and privatization of airports. ${ }^{75}$ Slot controls may be undesirable because, depending on their design, they can reduce competition and raise equity concerns among carriers. ${ }^{76}$ Construction of new airports is necessary, if only to meet future air capacity demands. But congestion pricing reduces the immediate need for this new capacity. Finally, some have argued for the privatization of airports to facilitate efficient pricing. ${ }^{77}$ We believe, however, that publicly provided and efficiently priced airports are preferable to private airports that could set inefficiently high prices. ${ }^{78}$

73. It may be desirable to institute limits on revenue (for example, parking fees) derived from nonairline tenants.

74. The stimulating effect that this "rebate" would have on demand would not offset the effect of the increased landing fees because the landing fees are time- and placespecific, whereas the rebate would apply to all flights.

75. Technological solutions to congestion, such as microwave landing systems, have also been proposed. However, as will be discussed in the section of the paper on air safety, many of these solutions are beset by technical problems and contractor delays.

76. Severin Borenstein, "On The Efficiency of Competitive Markets for Operating Licenses,' Quarterly Journal of Economics, vol. 103 (May 1988), pp. 357-85, argues that a market allocation of slots will not assure efficiency.

77. Report of the President's Commission on Privatization, Privatization: Toward More Effective Government (March 1988).

78. For example, based on our model, short-run landing fees at Anchorage airport under monopoly pricing result in a per passenger increase of more than $\$ 500$ compared 
Economists have advocated airport congestion pricing for at least twenty years. The recent explosion of air traffic makes its adoption imperative. The long-standing political concerns that have militated against congestion pricing may now be outweighed by new political realities. The public's plea for an end to flight delays and the need for more efficient expenditure of limited federal funds may be the basis for a political consensus that could make congestion pricing, and thus an improvement in the deregulated air system's performance, a real possibility.

\section{Air Safety}

Our carrier choice model, described in the opening section of the paper, shows that market forces provide strong incentives for carriers to conduct safe operations. Safety incentives are also provided by the liability insurance market and by capital markets. ${ }^{79}$

Despite these market forces, and despite the steady decline in fatalities per passenger-mile flown since commercial aviation began, concerns about air safety have risen dramatically during the past few years. The blame generally attaches to deregulation. We argue there is cause for concern, not because of deregulation per se, but because of mismanagement. The FAA, DOT, and Congress have failed to manage effectively the technological and manpower needs that have arisen in the deregulated environment. Unlike current congestion and merger policies that have already harmed performance in the deregulated environment, the malignant effects of mismanaged air safety have yet to surface. If mismanagement continues, however, there will be a perceptible decline in air safety.

\section{Deregulation and Air Safety}

Given the long-run trend toward greater safety (figure 2), deregulation could have impaired safety only if safety improvements would have been even greater had regulation continued. Analyzing this issue in a concep-

with a $\$ 1.60$ per passenger increase under congestion pricing. Net benefits under monopoly are lower than currently.

79. Steven A. Morrison and Clifford Winston, "Air Safety, Deregulation, and Public Policy," Brookings Review, vol. 6 (Winter 1988), pp. 10-15, show that airline insurers monitor safety through rates that reflect expected settlement costs. Andrew Chalk, "Air Travel: Safety through the Market," CATO Policy Report, vol. 9 (July-August 1987), 
Figure 2. Fatal Accidents per 100,000 Departures, U.S. Certificated Air Carriers, 1949-88

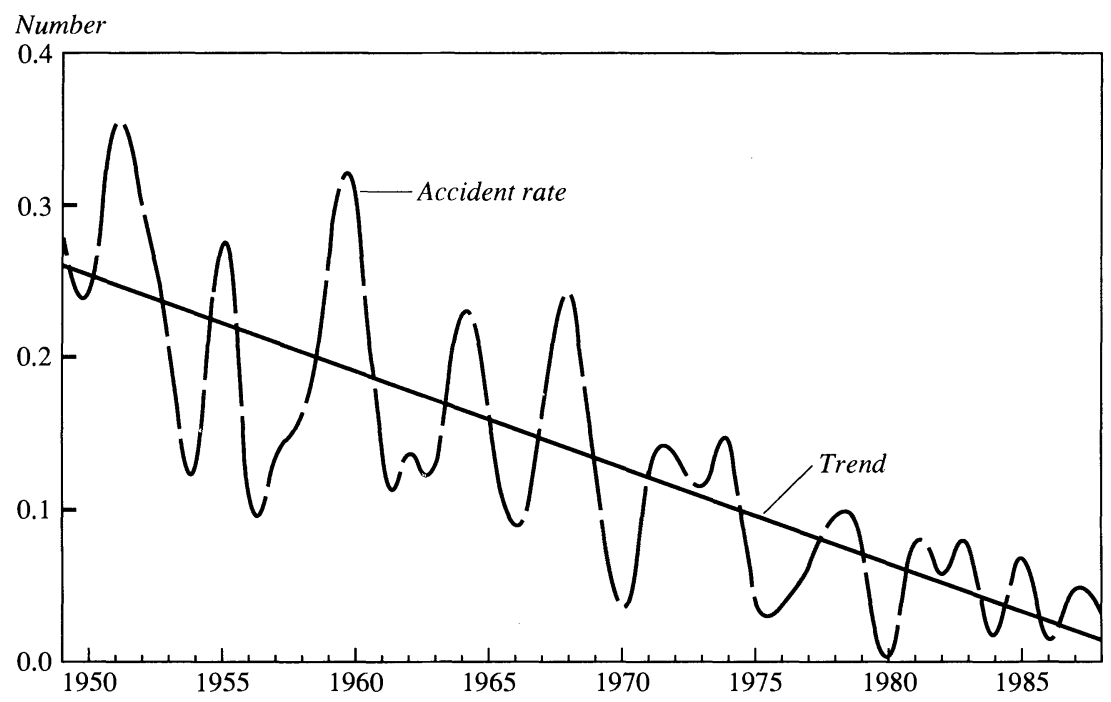

Source: Air Transport Association.

tually correct way is probably not possible: the appropriate counterfactual would ask how safety under deregulation compares with what safety would have been under regulation, all else equal. Using regression analysis to estimate the impact of regulatory policy on the accident rate would require controlling for other influences, including the primary causes of most accidents and the most difficult to measure (pilot error and weather). The sample should also include only accidents that are a priori partly caused by regulatory policy..$^{80}$ Other accidents, which make up the bulk of all accidents, add considerable noise to the dependent variable.$^{81}$ One is thus left with the challenge of explaining an arbitrary

p. 15, and Don M. Chance and Stephen P. Ferris, "The Effect of Aviation Disasters on the Air Transport Industry: A Financial Market Perspective," Journal of Transport Economics and Policy, vol. 21 (May 1987), pp. 151-65, report that aircraft and airline stockholders sustain losses from a crash.

80. If such a sample could be constructed, regression analysis would probably not be necessary to identify regulatory policy's effect on safety.

81. As an analogous point, if one were solely interested in estimating households' price elasticity of demand for oranges, it would not be desirable to specify the quantity of all food consumed by the household as the dependent variable. 
Table 16. Major Contributors to Fatal Commercial Air Accidents, 1965-86

\begin{tabular}{|c|c|c|c|c|}
\hline \multirow[b]{2}{*}{ Contributor } & \multicolumn{2}{|c|}{$1965-75$} & \multicolumn{2}{|c|}{$1976-86$} \\
\hline & $\begin{array}{c}42 \text { accidents, } \\
10 \text { midair }\end{array}$ & $\begin{array}{c}\text { Order of } \\
\text { importance }\end{array}$ & $\begin{array}{l}15 \text { accidents, } \\
1 \text { midair }\end{array}$ & $\begin{array}{l}\text { Order of } \\
\text { importance }\end{array}$ \\
\hline Pilot error & 32 & 1 & 12 & 1 \\
\hline Weather & 18 & 2 & 8 & 2 \\
\hline Traffic control & 9 & 3 & 5 & 3 \\
\hline Aircraft or engine & 7 & 4 & 4 & 4 \\
\hline Maintenance & 2 & 5 & 1 & 6 \\
\hline Airport facilities & 0 & 6 & 2 & 5 \\
\hline
\end{tabular}

Source: Steven A. Morrison and Clifford Winston, "Air Safety, Deregulation, and Public Policy," Brookings Review, vol. 6 (Winter 1988), p. 12.

Table 17. Characteristics of Pilots in Fatal Accidents, 1965-86

\begin{tabular}{lcc}
\hline \multicolumn{1}{c}{ Characteristic } & $\begin{array}{c}1965-75 \\
\text { average }\end{array}$ & $\begin{array}{r}1976-86 \\
\text { average }\end{array}$ \\
\hline $\begin{array}{l}\text { Pilot age } \\
\text { Pilot total flying hours } \\
\begin{array}{c}\text { Pilot total flying hours in } \\
\text { aircraft type in accident }\end{array}\end{array}$ & $\begin{array}{r}44.95 \\
14,622\end{array}$ & 17,488 \\
& 2,481 & 4,329 \\
\hline
\end{tabular}

Source: Morrison and Winston, “Air Safety, Deregulation, and Public Policy,” p. 12.

handful of accidents, while having to control for at least two effects that are extremely difficult to measure.

An alternative approach is to investigate whether deregulation has affected the underlying causes of airline accidents. Critics charge that deregulation has led firms to cut costs at the expense of safety. If so, one would expect to see a higher incidence of maintenance-related accidents or a reduction in the average age and experience of pilots involved in accidents. Table 16 reveals that the relative importance of the causes of accidents has not been altered by deregulation. Further, maintenancerelated accidents and midair collisions have fallen, and, as shown in table 17, pilots involved in accidents are older and more experienced. Thus when we look at the causes of accidents, it is difficult to find support for the hypothesis that deregulation has adversely affected the long-run safety trend by inducing carriers to engage in cost cutting that has compromised the margin of safety.

What has been responsible for the downward trend in fatal accidents, and how can this trend be maintained? Industry learning in conjunction 
Table 18. FAA Revenues

Billions of dollars

\begin{tabular}{lcccccc}
\hline \multicolumn{1}{c}{ Source } & 1982 & 1983 & 1984 & 1985 & 1986 & 1987 \\
\hline Trust fund & 1.593 & 2.805 & 2.007 & 3.720 & 2.532 & 2.585 \\
General fund & 1.541 & 1.464 & 2.644 & 1.635 & 2.340 & 2.361 \\
Total & 3.134 & 4.269 & 4.651 & 5.355 & 4.872 & 4.946 \\
\hline
\end{tabular}

Source: Report of the President's Commission on Privatization, Privatization: Toward More Effective Government (March 1988), p. 70.

with the introduction of radar, jet aircraft, improved navigational and landing aids, and pilot training more closely aligned to actual lifethreatening situations have caused the long-run decline in accidents. If the trend is to continue, further progress must be made in reducing the leading causes of accidents-pilot error and weather effects-and in preventing the incidence of traffic control and maintenance errors from rising because the safety surveillance work force is not aligned with the volume of traffic.

\section{Air Safety Management and Performance}

Is the current approach to managing air safety conducive to rapid implementation of the most effective technology at least cost? Is the technology being complemented by a labor force of adequate size and expertise?

The Federal Aviation Administration, an agency within the Department of Transportation, is currently responsible for air safety. Its tasks amount to inspection of aircraft and enforcement of safety regulations, weather communications, air traffic control, and selection and training of controllers. Slightly more than half the FAA's funding is from the aviation trust fund (table 18), which is largely composed of revenues from the aviation ticket tax. ${ }^{82}$ Remaining FAA revenues are from the general funds. All FAA expenditures are included in the federal budget.

Institutional sources of friction. As a part of DOT, FAA's policy and funding must be coordinated with those of the department, and FAA initiatives must compete for priority with those related to highways, mass transit, and so forth. Differences in policy have arisen, for example,

82. Policies for the Deregulated Airline Industry, p. 39, estimates the domestic ticket tax accounts for 88 percent of trust fund revenues. 
in imposing new safety standards because the FAA's concern with air commerce and its closeness to the industry makes it more reluctant than DOT to impose more regulations on the industry. Friction has also arisen because DOT procedures and reviews and Office of Management and Budget cost-benefit evaluations slow FAA receipt of funds. Like all government agencies, the FAA also needs political support for its activities from the administration and authorization approvals and appropriations from Congress. Its funding is thus vulnerable to spending cuts aimed at reducing the federal budget deficit.

Effects on performance. The FAA's organizational status within DOT and congressional and administration control over its spending have resulted in a constrained and inefficient agency. ${ }^{83}$ Critics also argue that the FAA's ineffective management stifles performance regardless of its institutional entanglements. The combined result is poor performance in the important areas concerned with weather-related accidents, pilot error, and the alignment of work force levels and air traffic technology with traffic volumes and patterns.

The Advanced Automated (Air Traffic) System, initially expected to cost $\$ 16$ billion, is designed to provide a flexible, computer-oriented air traffic control system capable of handling the increased traffic volumes of the future at reduced manpower needs. The system also includes major improvements in detecting wind shear, the primary cause of several crashes, including two major ones in the 1980s. But delays and inefficiencies have characterized the development of the system. Cost overruns are in the billions (the completed system is now expected to cost $\$ 24$ billion), and, as shown in table 19, most projects are seriously behind schedule. The full system is nearly a decade behind schedule and is not expected to be completed until the next century.

The FAA does not have a centralized and systematic approach to improving flight crew performance despite its obvious importance. Further, pilot selection and training rules have not been substantially revised in decades, and cockpit design requirements ignore much of what is known about the human factors involved in piloting an airplane. ${ }^{84}$

83. For a discussion of the specific problems caused by the FAA's organizational status, see Aviation Safety Commission, Volume I: Final Report and Recommendations (April 1988).

84. Office of Technology Assessment, Safe Skies for Tomorrow: Aviation Safety in a Competitive Environment (July 1988). 


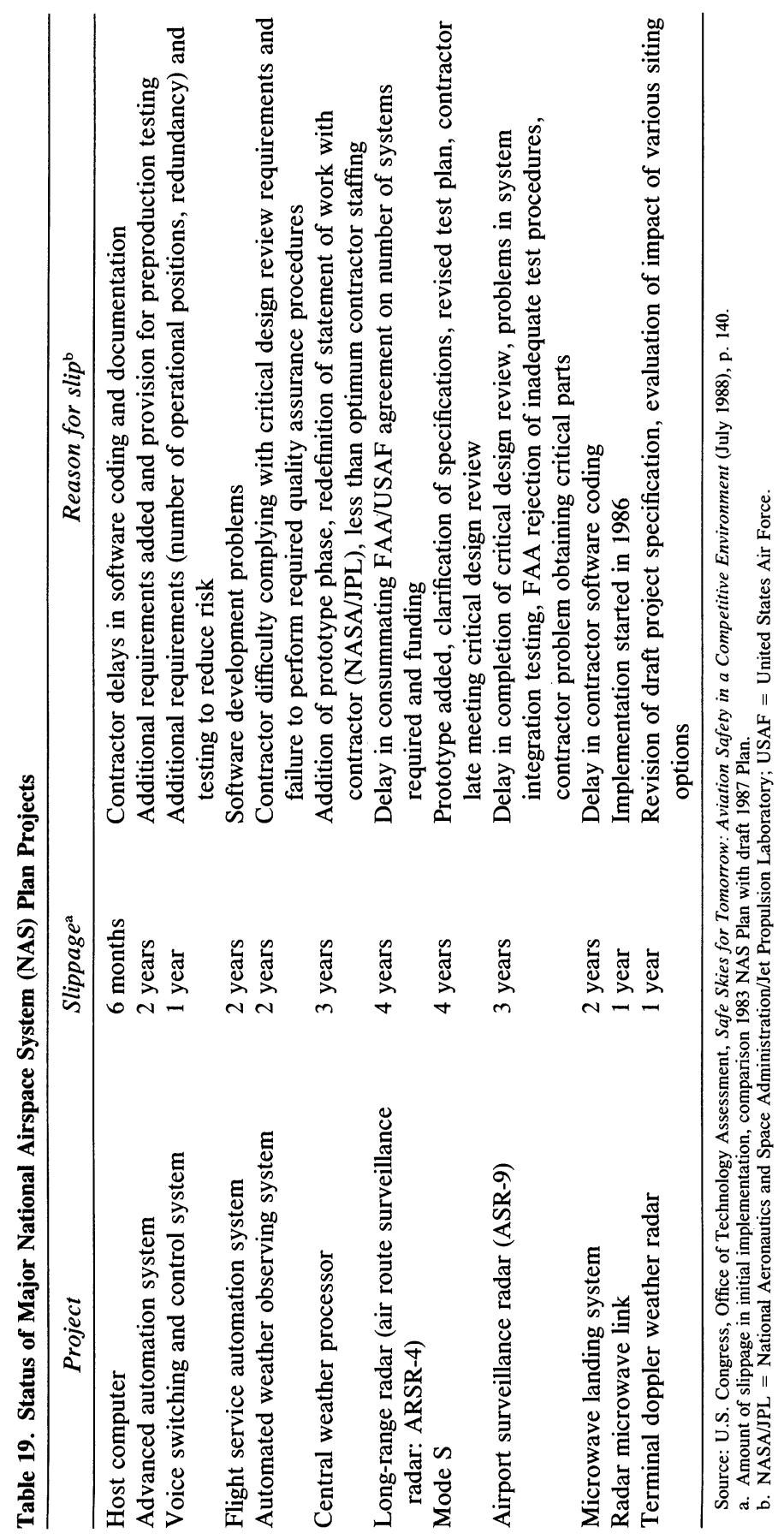


The number of controllers and inspectors has not kept pace with the growth of air travel, especially during the past few years (table 20). Despite congressional prodding that has increased the controller work force to 16,250 , fewer controllers are at work today than were at work during 1978-80. Defenders of the FAA point to bureaucratic delays imposed by DOT and Congress and to the dismissal of the PATCO strikers, but the FAA deserves criticism for failing to anticipate and to act upon the need for additional manpower under deregulation. ${ }^{85}$

\section{Solutions}

Several solutions have been proposed to improve air safety management. The most prominent ones are to separate the FAA from DOT and establish it as an independent agency whose expenditures are not part of the federal budget or to privatize the airport and en-route portion of air traffic control, keeping the FAA responsible for safety. ${ }^{86}$

Neither of these approaches attempts explicitly to accomplish what we view as the primary objectives of air safety management: efficient introduction of state-of-the-art technological innovations that ensure continuation of the long-term safety trend and efficient conduct of daily operations. These objectives require a flexible, adaptive FAA with the ability to manage technological change effectively. ${ }^{87}$ One possibility is to reorganize the FAA, establishing a tactical branch concerned with daily operations, such as air traffic control, and a strategic branch concerned with long-term safety planning, for example, long-range technical development of the air traffic control system.

85. It has been argued that the FAA believed the technological advances in the air traffic control system could reduce manpower needs. While this may be correct, the new air traffic control system is far from complete, and the agency has lacked the flexibility to adapt to change in its environment.

86. For a full discussion of recommendations to make the FAA an independent agency, see Volume I: Final Report and Recommendations. For a recommendation on privatizing the agency, see Privatization.

87. The FAA is by no means alone among federal agencies in having difficulties managing long-term planning phased with short-term budget cycles. The problem is particularly acute for agencies that must manage technological change involving procurement of costly computers and data processing equipment. See, for example, Office of Technology Assessment, The Social Security Administration and Information Technology-Special Report (September 1986); and Office of Technology Assessment, Hospital Information Systems at the Veterans Administration-Special Report (September 1987). 
Table 20. Selected FAA Employee Totals and Total Flight Departures, 1978-87

\begin{tabular}{|c|c|c|c|c|}
\hline Year & $\begin{array}{l}\text { Air traffic } \\
\text { controller }^{\mathrm{a}}\end{array}$ & $\begin{array}{c}\text { Aviation } \\
\text { safety inspector }\end{array}$ & $\begin{array}{l}\text { Electronics } \\
\text { technician }^{\mathrm{c}}\end{array}$ & $\begin{array}{l}\text { Departures } \\
\text { (thousands) }\end{array}$ \\
\hline 1978 & 16,750 & 1,466 & 9,423 & 5,013 \\
\hline 1979 & 16,853 & n.a. & 9,209 & 5,399 \\
\hline 1980 & 16,584 & 1,499 & 8,871 & 5,352 \\
\hline 1981 & 6,658 & 1,615 & 8,432 & 5,211 \\
\hline 1982 & 11,416 & 1,423 & 8,031 & 4,963 \\
\hline 1983 & 11,946 & 1,331 & 7,633 & 5,033 \\
\hline 1984 & 11,944 & 1,394 & 7,229 & 5,488 \\
\hline 1985 & 12,245 & 1,475 & 6,856 & 5,835 \\
\hline 1986 & 12,429 & 1,813 & 6,600 & 6,426 \\
\hline 1987 & 12,847 & 1,939 & 6,740 & 6,570 \\
\hline
\end{tabular}

Sources: Office of Technology Assessment, Safe Skies, p. 17. Departures are from the Air Transport Association. n.a. Not available.

a. Full performance level and developmental controllers at towers and centers.

b. Air carrier inspectors (approximately 40 percent of the total) were responsible for 145 air carriers, while general aviation inspectors were responsible for 173 Part 135 commuter airlines, 7,804 other commercial aircraft operators, and 5,210 aviation schools and repair stations as of March 10, 1988.

c. Communications, navigational aid, radar, and automation technicians.

Top-level management would have to coordinate the activities of the tactical and strategic branches, while separating them to avoid biasing long-range activities. At the same time, it would have to keep the strategic branch abreast of the evolving needs of operations to prevent long-term planning from being an empty exercise. Second, the strategic branch, in particular, must be staffed with technically competent people continually exposed to the frontiers of knowledge, for example, through programs for visiting researchers. Finally, stable funding must be provided and procurement and staffing procedures especially tailored to facilitate the objectives of the strategic branch. ${ }^{88}$ Funding could be made more stable by separating FAA from DOT, reducing the dependence on general funds by instituting efficient landing fees discussed previously, and using the (lower) ticket tax for supplementary revenues. General funds that are needed should be authorized and appropriated on a multiyear basis, to avoid drastic year-to-year fluctuations that make long- and short-term operations difficult.

Implementing our proposal would not be easy. Considerable logistical and political problems would have to be resolved. However, it is clear

88. Safe Skies reports that at least 75 percent of the FAA's budget is spent on current operations, which leaves little money to invest in long-term planning activities. 
that current air safety management has been seriously deficient in coping with the changes brought about by deregulation. As a result, deregulation itself rather than governmental mismanagement has been unfairly accused of reducing safety.

Thus far, this management failure has not reversed the long-term air safety trend. But a more focused approach to managing air safety, such as proposed here, is necessary or a real decline in air safety will be inevitable.

\section{Learning from This Assessment}

Public policy toward airline mergers, airport capacity utilization, and air safety has not been responsive to the changes in the air transportation system brought by deregulation and has consequently lowered social welfare in the long run. The costs of these policy failures have been magnified because each has had adverse effects on other aspects of the system: mergers have strengthened individual carriers' control of major airports, making it easier for them to block pricing innovations that could curb congestion; failure to deal with congestion effectively has jeopardized safety and has led to limits on operations that reduce competition; mismanagement of air safety has increased congestion and led to calls to decrease airport activity, thus hurting competition.

What can be learned from this assessment? First, practical solutions to the problems at hand present themselves. The policy changes we have proposed constitute the foundations of a plan for Samuel Skinner, the new secretary of transportation. In particular, future merger decisions should be based on a broader and longer-run view of the effects of mergers on network development and competition. To help minimize the impact of previous decisions on competition, the secretary should take the lead in promoting foreign carrier entry and reciprocal agreements with other countries. Such a reform would not only enhance domestic competition, but perhaps pave the way for deregulation of international flights. The secretary should also remove any legal obstacles to and promote the use of airport congestion pricing. In addition, pricing "innovations" should be applied to all carriers with the objective of regulating the use of scarce runway capacity during peak periods. It should not be applied just to one type of carrier (general aviation), as 
was recently the case at Boston's Logan Airport. Although the policy at Logan probably increased net welfare, it was politically insensitive and thus jeopardized the introduction of more beneficial types of congestion pricing. Finally, the secretary should recognize that the Federal Aviation Administration's objectives could be better achieved if it were an independent agency. The Department of Transportation should not oppose a separation of responsibilities.

Beyond the matter of practical solutions to existing problems, it is important to explain why policy that compromised the performance of the deregulated air system was formulated. Given that Congress passed the deregulation legislation and still supports it, and that the FAA and DOT are administered by appointees made by a pro-deregulation administration, it is difficult to see how legislative and bureaucratic interests would be served by policies that on balance harm air system performance. Local governmental interests may partially explain why airports have not strongly advocated efficient tolls; but this behavior cannot be easily extended to the national level, especially when such tolls could lower federal spending.

Our explanation is that errors in forecasting deregulation's long-term effects on traffic volumes and patterns are responsible for the counterproductive policies. Deregulation's architects did not foresee the need to establish an advisory body that would be responsible for guiding the air system's transition to a stable deregulated equilibrium. The agencies assigned specific tasks misjudged deregulation's effect on their area of responsibility. ${ }^{89}$

The Airline Deregulation Act of 1978 quickly phased the Civil Aeronautics Board out of existence. (Coincidentally, its complete elimination on January 1, 1986, just preceded the appearance of major problems in the air system.) Specific responsibilities were parceled out to the FAA and DOT. The FAA, whose long-standing responsibility for safety was

89. Dennis Sheehan and Clifford Winston, "Expectations and Automobile Policy,"' in Clifford Winston and Associates, Blind Intersection? Policy and the Automobile Industry (Brookings, 1987), argue that congressional misperceptions of the effects of various legislation hurt the welfare of automobile consumers and producers. Similarly, Michael E. Levine, "Revisionism Revised? Airline Deregulation and the Public Interest," Law and Contemporary Problems, vol. 44 (Winter 1981), pp. 179-95, argues that airline regulation was imposed by a Congress that, while attempting to act in the public interest, made a mistake. 
not affected by deregulation, acknowledged that it was "caught unprepared and underestimated the changes deregulation would bring." 90 DOT, taking over the CAB's responsibility for evaluating mergers, had no long-run vision of the industry and simply passed on the administration's sympathies. ${ }^{91}$ DOT's approach toward congestion and delays amounted to coaxing carriers to limit operations and to report on-time performance. ${ }^{92}$

Although it is understandable that architects of deregulation believe that it is necessary to eliminate all vestiges of regulation quickly, if only to make it difficult to reregulate, such zeal may prove counterproductive in the long run. The reputation of airline deregulation and the performance of the air system have been harmed by policies that could have been avoided had provisions been made for an advisory body responsible for guiding the air system's transition. ${ }^{93} \mathrm{~A}$ forceful advocate in the policymaking arena was needed to point out existing policies' incompatibilities with deregulation and to articulate the need for greater caution in judging the anticompetitive effects of mergers, for congestion pricing at airports, and for an adaptive and visionary FAA.

Fortunately, it is not too late for other industries to learn from the air experience. Because it is probably too late to form a transitional advisory body for surface freight transportation, the Interstate Commerce Commission should not be forced to close its doors. It can still help the freight transportation system in its transition to full deregulation by promoting policies toward captive railroad shippers and collective ratemaking that are compatible with unregulated competition. As deregulation evolves in telecommunications, banking, and natural gas, an advisory body

90. Statement by Bob Buckhorn, FAA spokesman, quoted in Laura Parker, "FAA Controller Work Force Back to Prestrike Strength,' Washington Post, October 2, 1988.

91. To be sure, one could make a case that these sympathies were consistent with a plausible ex ante benefit-cost evaluation.

92. One could also argue that this was the best policy DOT could pursue given their authority.

93. The members of this transitional advisory body could have been drawn from the $\mathrm{CAB}$, other areas of government, industry, and academia. It would have been important that those people taken from the $\mathrm{CAB}$ not promote their agency's regulatory interests, but contribute to the advisory body's goal of managing a smooth regulatory transition. The "usual group of suspects"' (Alfred Kahn, Elizabeth Bailey, Michael Levine) could easily have met this criterion for membership. 
should be established to manage a transition in these industries that promotes the goals of deregulation. ${ }^{94}$

Despite the overwhelming evidence that airline deregulation has produced significant gains for society, ineffective management of the regulatory transition has provided an opening for advocates of reregulation. Proponents of deregulation have great incentives to prevent this from happening elsewhere.

\section{Appendix: The Theory of Optimal Runway Pricing and Investment}

We place each aircraft operating at an airport into one of six mutually exclusive user classes (international, cargo, majors and nationals, commuter, other commercial [primarily regionals], and general aviation). During a particular hour of the day the inverse demand for arrivals is expressed as $P_{A t}^{i}\left(Q_{A t}^{i}\right)$, where $P_{A t}^{i}$ is the "gross" price of an arrival by user class $i$ during period $t$ and $Q_{A t}^{i}$ is the number of arrivals by user class $i$ during period $t$. The inverse demand for departures is defined similarly with the subscript $D$ replacing subscript $A$.

The (average) delay in minutes experienced by an arrival $\left(T_{A}\right)$ or departure $\left(T_{D}\right)$ during period $t$ depends on the number of arrivals and departures by each user class during that period and on runway capacity $R W$ :

$$
\begin{aligned}
T_{A t} & =T_{A}\left(Q_{A t}^{1}, \ldots, Q_{A t}^{6}, Q_{D t}^{1}, \ldots, Q_{D t}^{6}, R W\right) \\
T_{D t} & =T_{D}\left(Q_{A t}^{1}, \ldots, Q_{A t}^{6}, Q_{D t}^{1}, \ldots, Q_{D t}^{6}, R W\right) .
\end{aligned}
$$

Each minute of arrival delay and departure delay is valued by users in

94. This body should be bipartisan, with a finite lifetime. One option, to ensure its independence from an administration's political pressures (either anti- or blindly proderegulation), would be a congressionally chartered body with an automatic sunset provision. This body's mandate would be strategic thinking about the long-term effects of deregulation, anticipating how and where these effects would stress the evolving equilibrium. Its task would be to formulate contingency plans and policy advice, not to manage the industry's daily operations. 
class $i$ at $V_{A}^{i}$ and $V_{D}^{i}$, respectively. These values include aircraft operating costs (which differ for arrivals and departures) and passenger (or cargo) time costs. $F C_{A t}^{i}$ and $F C_{D t}^{i}$ represent undelayed flight costs for arrivals and departures by a user in class $i$ during period $t$.

Finally, (daily) airport capacity-related costs are expressed as $\rho(R W)$, while airport use-related costs (maintenance, operations, and administration) are given by $M\left(Q^{1}, \ldots, Q^{6}\right)$, where $Q^{i}$ is the (daily) total arrivals and departures by users in class $i$.

Given these variable definitions, the daily net benefits of airport use can be expressed as

$$
\begin{aligned}
N B= & \sum_{t=1}^{24} \sum_{i=1}^{6}\left\{\int_{0}^{Q_{A t}^{i}} P_{A t}^{i}\left(Q_{A t}^{i \prime}\right) d Q_{A t}^{i^{\prime}}-Q_{A t}^{i} F C_{A t}^{i}\right. \\
& -V_{A}^{i} Q_{A t}^{i} T_{A}\left(Q_{A t}^{1}, \ldots, Q_{A t}^{6}, Q_{D t}^{1}, \ldots, Q_{D t}^{6}, R W\right) \\
& +\int_{0}^{Q_{D t}^{i}} P_{D t}^{i}\left(Q_{D t}^{i \prime}\right) d Q_{D t}^{i \prime}-Q_{D t}^{i} F C_{D t}^{i} \\
& \left.-V_{D}^{i} Q_{D t}^{i} T_{D}\left(Q_{A t}^{1}, \ldots, Q_{A t}^{6}, Q_{D t}^{1}, \ldots, Q_{D t}^{6}, R W\right)\right\} \\
& -M\left(Q^{1}, \ldots, Q^{6}\right)-\rho(R W) .
\end{aligned}
$$

The first-order conditions for a maximum are:

$$
\begin{aligned}
& \frac{\partial N B}{\partial Q_{A t}^{i}}=P_{A t}^{i}-F C_{A t}^{i}-V_{A}^{i} T_{A t}-\left(\sum_{i=1}^{6} V_{A}^{i} Q_{A t}^{i}\right) \frac{\partial T_{A t}}{\partial Q_{A t}^{i}} \\
& -\left(\sum_{i=1}^{6} V_{D}^{i} Q_{D t}^{i}\right) \frac{\partial T_{D t}}{\partial Q_{A t}^{i}}-\frac{\partial M}{\partial Q_{A t}^{i}}=0 \quad \begin{aligned}
i & =1, \ldots, 6 \\
t & =1, \ldots, 24,
\end{aligned}
\end{aligned}
$$

(2) $\frac{\partial N B}{\partial Q_{D t}^{i}}=P_{D t}^{i}-F C_{D t}^{i}-V_{D}^{i} T_{D t}-\left(\sum_{i=1}^{6} V_{A}^{i} Q_{A t}^{i}\right) \frac{\partial T_{A t}}{\partial Q_{D t}^{i}}$

$$
-\left(\sum_{i=1}^{6} V_{D}^{i} Q_{D t}^{i}\right) \frac{\partial T_{D t}}{\partial Q_{D t}^{i}}-\frac{\partial M}{\partial Q_{D t}^{i}}=0 \quad \begin{aligned}
& i=1, \ldots, 6 \\
& t=1, \ldots, 24
\end{aligned}
$$

(3) $\frac{\partial N B}{\partial R W}=\sum_{t=1}^{24} \sum_{i=1}^{6}\left\{-V_{A}^{i} Q_{A t}^{i} \frac{\partial T_{A t}}{\partial R W}-V_{D}^{i} Q_{D t}^{i} \frac{\partial T_{D t}}{\partial R W}\right\}-\frac{\partial \rho}{\partial R W}=0$. 
If equations 1 and 2 were solved for the $P$ 's, we would have the familiar rule that (gross) price for each user class and time period should equal marginal cost. However, because each user necessarily bears flight costs and (own) delay costs, we obtain the optimal user charge (toll) by subtracting these terms from $P$.

$$
\begin{aligned}
\operatorname{Toll}_{A t}^{i}= & P_{A t}^{i}-F C_{A t}^{i}-V_{A}^{i} T_{A t}=\left(\sum_{i=1}^{6} V_{A}^{i} Q_{A t}^{i}\right) \frac{\partial T_{A t}}{\partial Q_{A t}^{i}} \\
& +\left(\sum_{i=1}^{6} V_{D}^{i} Q_{D t}^{i}\right) \frac{\partial T_{D t}}{\partial Q_{A t}^{i}}+\frac{\partial M}{\partial Q_{A t}^{i}} \quad \begin{array}{l}
i=1, \ldots, 6 \\
t=1, \ldots, 24,
\end{array} \\
\operatorname{Toll}_{D t}^{i}= & P_{D t}^{i}-F C_{D t}^{i}-V_{D}^{i} T_{D t}=\left(\sum_{i=1}^{6} V_{A}^{i} Q_{A t}^{i}\right) \frac{\partial T_{A t}}{\partial Q_{D t}^{i}} \\
& +\left(\sum_{i=1}^{6} V_{D}^{i} Q_{D t}^{i}\right) \frac{\partial T_{D t}}{\partial Q_{D t}^{i}}+\frac{\partial M}{\partial Q_{D t}^{i}} \quad \begin{array}{l}
i=1, \ldots, 6 \\
t=1, \ldots, 24 .
\end{array}
\end{aligned}
$$

The term on the far right of the first line of equation 4 represents the extra cost that an additional arrival by a user in class $i$ during period $t$ imposes on arrival operations in all user classes during the same period. The first term on the second line of 4 is the extra cost imposed on departure operations by all user classes during period $t$. The final term in equation 4 is marginal runway maintenance, operation, and administration expense. (Equation 5 is interpreted similarly.) Thus optimal arrival and departure tolls should equal the extra cost that that operation imposes on other users and on the airport authority.

Equation 3 shows that optimal capacity occurs when the savings in delay costs to all users during all time periods due to additional runway capacity equal the extra cost of that capacity. It can be shown that if the delay function is homogeneous of degree zero in the $Q$ 's and $R W$ (that is, if delay is a function of the volume-capacity ratio), optimal pricing with optimal investment will result in (runway) revenue to the airport equal to (runway) cost if $\rho(R W)$ exhibits constant returns to scale (that is, two runways cost twice as much as one). If decreasing returns exist revenue will exceed cost, while revenue will fall short of cost in the increasing returns case. 


\section{Comments and Discussion}

Elizabeth E. Bailey: I certainly agree with the main point in the Morrison and Winston paper, that the full benefits of airline deregulation have not been enjoyed. I also agree that the cause stems from the failure of the Civil Aeronautics Board to treat civil aviation policy as a complete system of interrelated elements. We did a partial equilibrium analysis, deregulating the rate-and-route authority that we had within the CAB, without fully addressing such policy issues as airport capacity and air traffic control. We did not initiate an airport plan that aligned well with the new freedom for rates and routes.

I think this lack of systemwide perspective was a strategic error. Certain requirements must be met for deregulation to yield its full benefits: competition and enforcement of measures and legal actions to sustain competition; merger policy that does not foreclose meaningful access to airports; policies to deal with overcrowding of terminals, gates, runways, and other facilities, and to provide for new capacity where warranted; and policies to add air traffic controllers and to introduce modern control technologies so that the system functions safely and efficiently. In sum, officials must look at the whole problem, as opposed to just looking at the problem that was within the $\mathrm{CAB}$ domain.

A secondary thrust of the paper aims at quantifying the effects of reduced competition. For example, the authors find that fares increase about 9 cents a mile if the number of actual competitors on a route is reduced from two to one, other things equal. If the number of carriers is reduced from three to two, fares increase by less than 1 cent a mile. So it is monopoly itself that confers pricing power; even a small dose of competition largely keeps such power at bay. I am like a kid in a candy store when presented with such results. Yet I am concerned that the 
authors place too much emphasis on the precise estimation of coefficients. I also have quibbles with some of the assumptions and some aspects of the econometric analysis. Since Alfred Kahn addresses these issues in some detail, I will not go into them further.

I also liked the paper for advocating airport policies that have both pricing and capacity components. At a conference about a year and a half ago at Northwestern University, dicussion of ways to solve the peak-load problem focused only on pricing. But there is need to ensure that the revenues collected from congestion tolls be used to relieve the overcrowding responsible for these additional charges. I am pleased that Morrison and Winston seek the full solution of actually looking at runway capacity as well as the tax concepts and tying the two together. I think there has to be a link between user fees and the purposes for which they are collected, which is not true now. A government mechanism must be found to enable that to happen.

Another area that needs to be explored relates to air traffic controllers. Before the air traffic control strike in the early 1980s, the separation between planes was only about five miles because of the controllers' high degree of experience. For most of the time since then, it has been twenty miles because of the the inexperience of the new work force. (I believe a separation of ten miles was instituted within the last year-still twice the pre-strike level.) In some places the low level of expertise of air traffic controllers contributes significantly to the kinds of delays the airlines are experiencing. Clearly the solution here requires a depoliticization of policy affecting controllers, adequate funds for hiring and training controllers, and better policies about sufficiently automating air traffic control.

I would like to know which contributes more to the congestion problem: air traffic control or runway capacity? An answer to that question would say a lot about whether congestion over the next twenty or twenty-five years could be handled through proper air traffic control policy or whether runway capacity needs to be built. Similarly, which is of greater concern, adding terminal space and capacity for people and baggage, or adding runway capacity? Could more joint use of military and civilian air facilities solve much of the capacity problem? I would like to see an assessment of such issues, which were not covered in this paper. Indeed, it seems to me that the first priority for the new secretary of transportation should be to examine the requirements for relieving 
congestion-whether these are best addressed through new airport construction or through other policy initiatives.

The authors suggest the formation of a transitional advisory body as part of any major policy change process, such as deregulation. If such a group had no authority and no power, I fear it would not be effective. But there may well be some way in which such a council could help either the secretary of transportation or the head of the Federal Aviation Administration. I think it would be useful to develop the idea further.

Indeed, I think analysts should explore not only economic solutions but also solutions that have to do with organizational form and with law. For example, if you could have been in Pittsburgh as the public authority was negotiating with USAir, you would have been greatly distressed. The process made it clear that the community would have to tear down or find a nonaviation use for the old passenger terminal, or else USAir would not put up the money for the new passenger terminal. Such virtual ownership of airports by cariers limits competition. A legal solution prohibiting such ownership or limiting its anticompetitive potential might make good policy sense. Similarly, organizational solutions need to be looked at, such as the authors' idea of an advisory council, or perhaps some form of privatization.

Alfred E. Kahn: Morrison and Winston have clearly been making the definitive evaluation of airline deregulation, and I am happy to comment on their latest installment. But I begin with two warnings. First, I am not certain I have fully comprehended every step of their exposition. Second, their conclusions accord so thoroughly with my own observations, not to say preconceptions, that it will take a great effort of will for me to be critical at all.

I will follow their organization.

\section{Air Traveler Preferences}

It is worth pondering more thoroughly than their paper does the extent to which the results of their consumer choice model are distorted by the authors' having been constrained to treat the travelers' choice of fare classifications as exogenous, that is, travelers first choose the fare class they want and then select carriers and routing on the basis, among other things, of their relative prices. 
Surely travelers decide also whether to travel by air at all and, where they have such an option, choose among carriers in important measure by whether discount fares are available. Discount traffic accounted for only 47 percent of the total back in 1978 (and perhaps only half of that in 1976), when the average discount from full fare was 35 percent; in contrast, discount mileage amounted to 82 percent of the total in 1983, and the average discount was 48 percent. A large part of the elastic response of demand must be attributable to the dramatic increase in the availability of those discounts. I suspect also that differences in the availability of discount fares for a particular trip affect the traveler's choice of carrier more powerfully than do differences among carriers in fares within a given category.

It follows that Morrison and Winston's measure of demand elasticity, derived only from consumers' response to fare differences among carriers within the same fare category, is an underestimate, probably by a wide margin. What significance does that underestimate have for their subsequent estimate of welfare losses caused by fare increases attributable to mergers? My initial inference was that it would cause the welfare losses to be understated: the more elastic the demand, the larger the welfare loss from an excess of price over marginal cost. Morrison and Winston point only to the other side of the coin: their model overstates the welfare loss, because it ignores the possibility of travelers escaping merger-induced price increases by shifting to a lower-fare class (see their note 3 ). Whether their observation tells the whole story, or correctly describes the net effect of their initial assumption, I am uncertain.

I would like to have the authors think more about their finding that the ownership of computer reservation systems "had an insignificant effect on carrier choice," in view of the widespread impression to the contrary. At first I thought that the influence of this variable might have been subsumed in their estimations under the hub variable, which is designed to capture promotional and reputation effects, but the authors tell us that the CRS variable remained insignificant when they removed the hub dummy (note 17). That finding would seem to be definitive. What remains to be understood, then, is why the airlines have engaged in such strenuous and costly efforts to acquire CRSs and to promote their adoption by travel agents. What causal relationship between dominant ownership of CRSs and dominant participation in traffic at particular localities may properly be inferred from such facts as that some 90 
percent of the travel agents in Dallas-Fort Worth are subscribers to American Airlines' Sabre system and more than 75 percent in Denver to United's Apollo, while a disproportionate percentage of travel agents in St. Louis use the TWA PARS and in Atlanta, the Delta system?

\section{The Economic Effects of Mergers}

Since Morrison and Winston devote most of their paper to the impact of mergers, I offer the opinion that the contribution of mergers to monopoly power in airlines has been grossly exaggerated; the mergers that have occurred are probably far more correctly regarded as a symptom of the inability of smaller carriers to compete with the hubdominant megacarriers than as a source of the megacarriers' monopoly power. The prime sources of that power are the competitive advantage enjoyed by the airline with the richest variety of flights into and out of a hub, feeding traffic to and from all its spokes; the preferential access it often enjoys to airport facilities there; and possibly its control of the computer reservation systems used by most of the travel agents at that location (although, as I have already observed, the Morrison-Winston results cast doubt on this factor). Other key elements are the override commissions and frequent flier credits megacarriers offer, both of which, being nonlinear, have the same effect as progressive quantity discounts or exclusive patronage refunds, and the way in which the megacarriers have learned to offer deeply discounted fares, selectively and discriminatorily, at levels far lower than their new, lower-cost competitors are charging or could possibly charge on a uniform basis. ${ }^{1}$

As I understand them, Morrison and Winston do not measure the actual effects of the mergers that have occurred. Instead, they use their estimates of the effect of such independent variables as the number of actual and potential competitors and the number of on-line and interline connections on such dependent variables as the level of fares, transfer time, and travel time to gauge the effects of the mergers on the basis of the ways in which they have changed those variables. It seems to me this procedure produces some biases in their results.

1. These factors were eloquently described by Michael Levine two years ago. See Michael E. Levine, “Airline Competition in Deregulated Markets: Theory, Firm Strategy, and Public Policy,' Yale Journal on Regulation, vol. 4 (Spring 1987), pp. 393-494. 
The main factor explaining the frequency of flights on a route, they find, is the number of competitors; a merger that reduces that number is therefore assumed to increase schedule delay. But the number of competitors must itself heavily depend on the density of traffic, which in turn greatly determines the frequency of flights. I cannot escape the suspicion that Morrison and Winston's estimate of the effect of a merger that reduces the number of actual competitors is likely to exaggerate the extent to which it will reduce flight frequency. The authors inform us (note 34 ) that including separate route density dummies neither changed the other parameter estimates nor improved their equations' explanatory power. I am compelled to assert my continued uncertainty: could it be their route density dummies were poorly designed? Is it always legitimate to carry over from cross-sectional analyses a relationship such as the one observed here between number of competitors and frequency of flights to predict the effect on the latter of a change over time in the former?

Operating in the opposite direction, I think, is their use of the same reasoning to predict a reduction in transfer time between flights when a merger converts what was interline to on-line connecting service. If two carriers each with half the gates and flights at a major airport merge, their union does not in itself reduce the distance travelers must walk in transferring from one plane to another. Doubtless if one carrier accounted for all the flights, it would try to schedule and locate them in such a way as to minimize passenger inconvenience in changing planes. The merger would thus probably result in a reduction in average distance and transfer time, but not, I should think, by as much as the difference that prevailed between on-line and interline transfers when there were two carriers.

This method is incapable also of picking up changes-improvements or deteriorations-in either efficiency or in other dimensions of service quality (see note 21) consequent on the mergers. The latter omission is particularly ironic, since surely the worst effect of the NorthwestRepublic merger from the standpoint of travelers-to judge from the complaints that continued to flow long thereafter-was the deterioration in quality of service, apparently attributable for the most part to the difficulty of integrating the two labor forces and their respective compensation schemes.

Finally, as Morrison and Winston point out, the increased value of frequent flier benefits, as they measure them, is critical to their estimation 
of whether mergers have on balance been beneficial to travelers. Like them, I am somewhat uneasy about how to evaluate this particular consequence. To the traveler it is an unequivocal benefit, one that probably could not have been provided equally well without a mergerthat is to say, by the two predecessor carriers pooling their frequent flier credits-since the attractiveness of these credits to the offering airline is their value as a competitive device. On the other hand, as Levine has noted, that value stems in part from their inducing travelers to make carrier choices that may not be in the interest of the parties who pay their fares; and, as Morrison and Winston observe, they have the unfavorable effect on travelers of severely impeding independent competitive challenges to hub-dominant carriers.

In the end, all I can say is amen to their conclusion about the need to take into account these indirect anticompetitive consequences of any future mergers. But I suspect they worry, as I do, that it is a trifle late in the day to lock that barn door. Future mergers, I fear, are likely to be able to get out through the back door of a failing-carrier defense.

\section{Congestion and Delays and Learning from This Assessment}

My three main comments are yes! yes! and yes!

As one of the witnesses in defense of Massport's new schedule of landing fees at Logan Airport, I helped persuade the federal district court of the relevance of marginal opportunity costs, ${ }^{2}$ only to be confronted with a later Department of Transportation decision disallowing the schedule on the grounds that it was both discriminatory and an illegitimate encroachment on federal authority. So I endorse with especial enthusiasm the Morrison-Winston recommendation that the U.S. government should bestow federal funds on airports only if they can show that their facilities are being efficiently used. I would require rather

2. "I understand what they are. That is the cost of using space and time, and to the extent that smaller planes use space and time, they should pay the fair price for it.

"The . . . studies . . . [of the complainants] ignore opportunity costs. They are based upon what I think is a flawed assumption that demands at Logan never exceed capacity. . . . But that premise I think is wrong, because it's clear that Logan does . . . experience serious congestion and serious delays." New England Legal Foundation v. Mass. Port Authority, D. Mass., Motion for Summary Judgment, transcript of the court's memorandum and order, delivered orally, June 29, 1988, pp. 23-24. 
than recommend congestion pricing as the way of satisfying this condition. ${ }^{3}$

The authors' finding that not only general aviation but also commuter operations would be "significantly curtailed under optimal pricing" deserves some additional consideration, both because it alludes to a powerful political impediment and because the prediction could be mistaken, as far as commuter operations are concerned. The objection by members of Congress from relatively sparsely populated areas to increased fees for commuter carriers raises a valid economic consideration: the external benefits of commuter operations in feeding traffic to the larger carrier operations at congested airports, since cost-based landing fees might erode such congestion. ${ }^{4}$

3. I quarrel mildly with their implication that the architects of deregulation did not foresee the need for such supplementary governmental policies. We clearly foresaw and pointed out to the Federal Aviation Administration the need for increased vigilance in the area of safety and the likelihood of increased airport congestion and the consequences of irrational airport access pricing. For instance, in March 1978 I gave a talk on "Route Awards and Airline Scheduling Practices"' to the FAA, in which I said:

"As I read through the list of topics and questions that were given to me by FAA as possible items to discuss, they all really seem to come down to one question, 'Can you people at the $\mathrm{CAB}$ [Civil Aeronautics Board] do more than you are doing to reduce those demands that you are placing upon us and the pressures that they are creating?' . . . There are three parts to my answer.

"The first part is no; I am not interested in helping you directly. I am not interested in directly controlling airline scheduling. . . . I am not interested in authorizing the carriers toget together and collaboratively regulate their schedules . . . and, therefore, the pressures that they impose on airport facilities. I am not interested in imposing arbitrary restraints on airline routing. . . .

"At a time when we at the $\mathrm{CAB}$ are trying to restore economic rationality to this industry ... to place increasing reliance on the competitive market to allocate scarce resources ... . we are not about to set about enthusiastically to intensify precisely those same kinds of arbitrary controls in order to solve the problem of limited airport space inefficiently.

"I don't suggest that these policies will suffice to solve your problems. . . . On the contrary, [they] will stimulate more air travel. . . .

"The allocation of scarce airport space is an economic problem just like any other economic problem ... and it will never be made intelligently until the users who are responsible for the incurrence of those costs on a marginal basis . . pay the full cost reckoned on a marginal or replacement basis. . .

"My moral is simply this to the FAA: if you're going to follow economically irrational policies, don't ask the CAB to bail you out by doing the same thing."

4. I recognized the possibility of such external benefits some seventeen years ago: "It could well be . . . that the offering of regular airline service in thin markets and off-season promotes the demand for service generally. If some line runs a feeder service from remote 
Part of the answer is that operations on the thinner routes would not necessarily be severely curtailed. Rather, sensible landing fees at congested airports would force commuter carriers to congregate travelers en route at smaller hubs and bring them to the congested one in larger planes. This result was said to have been observable at Logan during the few months in which the revised fees were applied.

The Morrison-Winston finding also ignores the possibility that if indeed, as is now widely understood, traffic feed to and from thin routes contributes to achieving economies of scale on denser routes (through the ability to use larger planes, for example), it would presumably be in the larger carriers' interest to compensate the commuters for the higher landing fees at peak hours (which translate into greater increases in cost per passenger on small than on large planes).$^{5}$ Larger carriers could, for example, change the distribution between them of revenues from joint fares.

The market cannot always be relied on to take externalities into account. Where the affected parties are few, however, as here, it may well do so.

\section{General Discussion}

Several participants observed that studies of the impact of regulation or deregulation must start from a more sophisticated theory of how competition works in the airline industry and of what causes airline mergers.

With regard to mergers, for example, Peter Reiss noted that the paper addresses only the effect of airline mergers on consumers, without asking why the mergers occur, what their consequences are in terms of operating

cities in upstate New York to New York City, it will, in so doing, also promote more air travel between New York and Miami. Similarly, if there are regular flights between New York and Miami in the off-peak, summer season, this may help promote travel in the busy winter as well-for example, the summer tourists, by providing additional net revenues to hotels, make possible lower rates during the peak season." I rejected the argument, however, on the erroneous understanding that there were no economies of scale to be achieved. Alfred E. Kahn, The Economics of Regulation: Principles and Institutions (Wiley and Sons, 1971; reprint, MIT Press, 1988), vol. 2, pp. 234-35.

5. This result was one reason the Department of Transportation in the Massport case concluded the new landing fees at Logan were discriminatory. 
costs and route structures, and what their full impact is on competition. Such information is obviously important in setting merger policy. Along these same lines, Michael Levine remarked that the paper had not tried to measure or take account of the potential synergies between computer reservation services (CRSs) and incentive commission structures. These possible synergistic effects suggest, as does Kahn in his comments, that the authors may have been too quick to dismiss the importance of CRSs in their model.

As to modes of competition, Nancy Rose observed that airlines often respond to changes in competitive conditions by changing the number of available seats at given prices rather than by changing prices. Levine added that they also change the allocation of seats to various fare classifications. Hence, he said, nominal fare levels may be a very poor proxy for actual price levels on a route.

Finally, Robert Hall pointed out that deregulation, by increasing "contestability," may not have had its intended effect of increasing competition, because the contestability argument also works in reverse. The fact that incumbents can instantly match lower fares or better service offered by a new entrant keeps entrants from gaining a toehold in the market. "Meeting the competition-the most competitive act," he commented, "prevents competition from operating." In consequence, "we have gone from regulation to monopoly," and the fact that some routes are effectively monopolized had led to underutilization of airport capacity in those routes. Winston suggested somewhat in jest that entrants could be protected by regulations that limit the frequency with which incumbent airlines can change their fares and routes. Levine said the idea had some appeal but was probably unworkable in practice. In addition, he was worried by the amount of power it would place in the hands of the regulatory authority.

Participants were also interested in the problem of airport congestion and the mix of pricing strategies, regulation, and free market forces that would solve this problem. Most participants seemed to believe that congestion-based pricing of airport fees, combined with regulation to ensure that the funds raised from these fees would go toward airport expansion, would go a long way toward eliminating the congestion. But Levine pointed out that the figures used in the paper for airport capacity expansion costs did not include environmental costs, a real social cost that he believes is not fully captured by land prices. He also expressed 
concern that if airport operators were left free to set airport-use taxes, they would not necessarily set fees to maximize efficient use of airport facilities. Instead they might come under political pressure to use the fund-raising potential of their monopoly position in airport services to finance other public services in the community, much as the Port Authority in New York has done to subsidize bus service for the Metropolitan Transit Authority.

William Nordhaus suggested, however, that the lesson to be learned from the airline deregulation experience is that "we should only deregulate uncongested industries," or, more rigorously, that we should "think very carefully about allowing price to fall to marginal cost in those industries where demand expansion will worsen congestion diseconomies."

On methodological issues, several participants expressed concern that the exact coefficient values generated by the Morrison-Winston regressions were being taken too literally. Rose observed that the results should be regarded as point estimates, based on representative consumers, average firms, or average network characteristics, and that they fail to take account of the underlying heterogeneity in the airline market. Recognizing this, and noting that it is always easy to pick out one set of numbers or assumptions and criticize them, she said it would be helpful to know how sensitive the results are to somewhat different assumptions or numbers. 